\title{
1 Rates and mechanisms of uranyl oxyhydroxide mineral dissolution
}

4 5

\author{
ESTELA REINOSO-MASET ${ }^{a, *}$, CARLI. STEEFEL ${ }^{b}$,WOOYONG UM ${ }^{c}$, JON \\ CHOROVER ${ }^{d}$ PEGGY A. O’DAY ${ }^{a}$
}

asierra Nevada Research Institute,University of CaliforniaMerced, 5200 North Lake Road, Merced, CA 95343, USA

${ }^{\mathrm{b}}$ Energy Geosciences Division, Lawrence Berkeley National Laboratory, 1 Cyclotron Road, M.S. 74R316C, Berkeley, CA 94720, USA

${ }^{\mathrm{C}}$ Energy and Environment Directorate,Pacific Northwest National Laboratory,P7-54, 902 Battelle Blvd., Richland, WA 99354, USA

${ }^{\mathrm{d} D e p a r t m e n t ~ o f ~ S o i l, ~ W a t e r ~ a n d ~ E n v i r o n m e n t a l ~ S c i e n c e, 1177 ~ E . ~ F o u r t h ~ S t ., ~ U n i v e r s i t y ~ o f ~}$ Arizona, Tucson, AZ 85721, USA

*Correspondence to: E. Reinoso-Maset, estela.reinosomaset@gmail.com, +1-209-724-4393

\section{ABSTRACT}

Uranyl oxyhydroxide minerals are important weathering products in uranium-contaminated surface and subsurface environments that regulate dissolved uranium concentrations.

However,dissolution rates for this class of minerals and associated dissolution mechanisms have not been previously reported for circumneutral $\mathrm{pH}$ conditions, particularly for the case of flow through porous media. In this work, the dissolution rates of K- and Na-compreignacite $\left(\mathrm{K}_{2}\left(\mathrm{UO}_{2}\right)_{6} \mathrm{O}_{4}(\mathrm{OH})_{6} \cdot 8 \mathrm{H}_{2} \mathrm{O}\right.$ and $\mathrm{Na}_{2}\left(\mathrm{UO}_{2}\right)_{6} \mathrm{O}_{4}(\mathrm{OH})_{6} \cdot 8 \mathrm{H}_{2} \mathrm{O}$ respectively) were measured using flow-through columns reactedwith two simulated background porewater (BPW) solutions of low and high dissolved total carbonatecontent (ca. 0.2 and $2.8 \mathrm{mmol} \mathrm{L}^{-1}$ ). Column materials were characterized before and after reaction with electron microscopy, bulk chemistry, and EXAFS to identify structural and chemical changes during dissolution and to obtain insight into molecularscale processes. The reactive transport code CrunchFlowwas used to calculate overall dissolution rates while accounting for fluid transport and changes in mineral volume and reactive surface area and results were compared to steady-state dissolution rate calculations.In low carbonate BPWsystems, interlayer $\mathrm{K}$ and Na were initiallyleached from both minerals, and in $\mathrm{Na}$ compreignacite, $\mathrm{K}$ and minor divalent cations from the input solution were incorporated into the mineral structure. Results of characterization analyses suggested thatafter reaction both K- and 
32 Na-compreignacite resembleda disordered K-compreignacite with altered surfaces. A 10-fold

33 increase in dissolved carbonate concentration and corresponding increase in $\mathrm{pH}$ (from 6.65 to

34 8.40) resulted in a net removal of $58-87 \%$ of total uranium mass from the columns, compared to

$35<1 \%$ net loss in low carbonate BPW systems.Steady-state release of dissolved uranium was not

36 observed with high carbonate solutions and post-reaction characterizations indicated a lack of

37 development of leached or altered surfaces. Dissolution rates (normalized to specific surface

38 area) were about 2.5-3 orders-of-magnitude faster in high versus low carbonate BPW systems,

39 with Na-compreignacite dissolving more rapidly than K-compreignaciteunder both BPW

40 conditions, possibly due to greater ion exchange $\left(1.57 \cdot 10^{-10} \mathrm{vs} .1 .28 \cdot 10^{-13} \mathrm{~mol} \mathrm{~m}^{-2} \mathrm{~s}^{-1}[\log \mathrm{R}=\right.$ -

419.81 and -12.89$]$ and $5.79 \cdot 10^{-10}$ vs. $3.71 \cdot 10^{-13} \mathrm{~mol} \mathrm{~m}^{-2} \mathrm{~s}^{-1}[\log \mathrm{R}=-9.24$ and -12.43$]$ for K- and Na-

42 compreignacite respectively).Experimental and spectroscopic resultssuggest that the dissolution

43 rate is controlled by bond breaking of a uranyl group and detachment from polyhedral layers of

44 the mineral structure. With higher dissolved carbonate concentrations, this rate-determining step

45 is accelerated by the formation of Ca-uranyl carbonate complexes (dominant species under these

46 conditions), which resulted in an increase of the dissolution rates.Optimization of both

47 dissolution rate and mineral volume fraction in the reactive transport model to account for

48 uranium mass removal during dissolution more accurately reproduced effluent data in high

49 carbonate systems, and resulted in faster overall rates compared with a steady-state dissolution

50 assumption. This study highlights the importance of coupling reaction and transport processes

51 during the quantification of mineral dissolution rates to accurately predict the fate of

52 contaminants such as uranium in porous geomedia.

\section{Keywords}

54 Uranyl oxyhydroxides, compreignacite, dissolution rate, reactive transport, EXAFS weathering of U(IV) oxide solids under oxidizing conditions (Hazen et al., 2009), corrosion of spent nuclear fuel in a geological repository(Finch et al., 1999), or potential precipitation from

59 liquid uranium (U) waste released directly into the subsurface (Zachara et al., 2007). In the

60 absence of dissolved phosphate or silicate, $\mathrm{U}(\mathrm{VI})$ has been observed to form a variety of 
61 crystalline and amorphous oxyhydroxide mineral phases in oxic subsurface environments

62 (Hunter and Bertsch, 1998; Morris et al., 1996) and in synthetic acidic-to-circumneutral

63 wastewaters (Kanematsu et al., 2014). The first oxidized alteration phase from the weathering of

64 synthetic or natural $\mathrm{UO}_{2}(\mathrm{~s})$ is typically a simple oxyhydroxide,either schoepite

$65\left(\left(\mathrm{UO}_{2}\right)_{8} \mathrm{O}_{2}(\mathrm{OH})_{12} \cdot 12 \mathrm{H}_{2} \mathrm{O}\right)$ or metaschoepite $\left(\left(\mathrm{UO}_{2}\right)_{4} \mathrm{O}(\mathrm{OH})_{6} \cdot 5 \mathrm{H}_{2} \mathrm{O}\right)($ Finch and Ewing, 1992).

66 Under most natural conditions, however, schoepite is metastable with a strong tendency to

67 undergo structural transformation to more stable secondary phases, such as becquerelite

$68\left(\mathrm{Ca}\left(\mathrm{UO}_{2}\right)_{6} \mathrm{O}_{4}(\mathrm{OH})_{6} \cdot 8 \mathrm{H}_{2} \mathrm{O}\right)$ or compreignacite $\left(\mathrm{K}_{2}\left(\mathrm{UO}_{2}\right)_{6} \mathrm{O}_{4}(\mathrm{OH})_{6} \cdot 7 \mathrm{H}_{2} \mathrm{O}\right)$ after incorporation of

69 Ca and K, respectively (Sandino and Grambow, 1994; Wronkiewicz et al., 1996). A Na analogue

70 of compreignacite $\left(\mathrm{Na}_{2}\left(\mathrm{UO}_{2}\right)_{6} \mathrm{O}_{4}(\mathrm{OH})_{6} \cdot 7\left(\mathrm{H}_{2} \mathrm{O}\right)\right)$ was tentatively identified among the alteration

71 phases observed on spent fuel in contact with groundwater for six years (Finch et al., 1999), and

72 is an important alteration phase due to the ubiquitous presence of dissolved Na in groundwaters

73 (Gorman-Lewis et al., 2008a). The thermodynamic solubility and dissolution rates of common

74 uranyl oxyhydroxidesplay a key role in controlling uranium release and mobility in

75 environmental scenarios (Finch and Murakami, 1999).Due to the high solubility and reactivity of

76 K-, Na- and Ca-uranyl oxyhydroxides compared with uranyl silicate and phosphate phases, their

77 importance in determining $U$ concentrations in saturated and unsaturated soils and sediments

78 may have been overlooked in prior studies.

As reviewed by Gorman-Lewis et al. (2008a), the solubility of K- and Na- compreignacite

80 has been rarely studied compared to the oxyhydroxide phases schoepite, metaschoepite, and

81 becquerelite (e.g., Giammar and Hering (2004),Sandino and Grambow (1994)). To our

82 knowledge, there have been only two studies investigating the thermodynamic solubility of the K

83 and Na end-members, both conducted as batch experiments. Sandino and Grambow (1994)

84 calculated the solubility product of synthetic compreignacite in $1 \mathrm{M} \mathrm{KCl}\left(\log K_{s p}=39.16 \pm 0.31\right)$

85 and observed no mineral phase alteration despite evidence of reduction in crystallinity based on

86 X-ray diffraction (XRD) powder data and scanning electron microscope (SEM) micrographs.

87 Gorman-Lewis et al. (2008b) carried out solubility measurements on different uranyl oxide

88 hydrate phases, including K- and Na-compreignacite, using solutions with pH between 4.0 to 5.3.

89 In their study, K-compreignacite solubility experiments reached steady-state conditions in 3 to 4

90 days from undersaturated solutions and in 7 to 14 days from supersaturated solutions, while Na-

91 compreignacite required between 2 and 20 days. Although the crystallinity of both minerals was 
92 reduced substantiallyby the end of the experiments, no phases other than K- and Na-

93 compreignacite were observed. For both minerals, dissolution was non-stoichiometric and excess

$94 \mathrm{~K}$ and Na was measured in solution. These minerals, along with becquerelite, share topologically

95 identical $\alpha-\mathrm{U}_{3} \mathrm{O}_{8}$ sheetsand have identical anion distribution(Burns, 1998; Burns and Li, 2002),

96 favoring cation leaching or exchange. Gorman-Lewis et al. (2008b) concluded that when steady-

97 state between the outer leached layer and the inner bulk material is achieved, the outer leached

98 layer also reached steady-state with the aqueous solution. The calculated solubility products of

99 end-member K- and Na-compreignacite differed by approximately 3.5 orders of magnitude (log

$100 \quad K_{\mathrm{sp}}=35.8$ and 39.4 for K- and Na-compreignacite, respectively), showing the large dependence

101 of mineral solubility on interlayer cation identity.

102 Other environmental parameters that influence uranyl mineral stability include $\mathrm{pH}$ and

103 dissolved carbonate concentration. In solution, uranyl in solution reactswith dissolved carbonate

104 and Ca, forming stable neutral or anionic carbonate, Ca-carbonate, and hydroxo-carbonate

105 aqueous complexes (Grenthe et al., 1992; Guillaumont et al., 2003). These complexes become

106 important above pH 4 and increase mineral solubility (Gorman-Lewis et al., 2008a), creating

107 mobile species that promote U(VI) migration in natural waters. Dissolution rates have not been

108 reported for any uranyl oxyhydroxide minerals, and differences in rates at different $\mathrm{pH}$ and

109 carbonate concentrations have not been investigated. Dissolution rate studies of other uranyl

110 mineral families included three uranyl silicates (Ilton et al., 2006; Pérez et al., 2000; Pérez et al.,

111 1996) and two uranyl phosphates (Gudavalli et al., 2013). In these studies, higher concentration

112 of dissolved carbonate and $\mathrm{pH}$ enhanced apparent mineral solubility or dissolution rate by 1 to 3

113 orders of magnitude, with the mechanism for U(VI) detachment attributed to the formation of

114 aqueous complexes of uranyl-carbonate and Ca-uranyl-carbonate species. Thus, in some prior

115 studies, dissolution rate laws were written as a function of bicarbonate concentration in order to

116 capture the dependence of the dissolution rate on the proposed mechanism(Pérez et al., 2000).

117 Most prior dissolution studies of uranyl mineralswere carried out as batch experiments,

118 although some studies employed continuously stirred tank flow-through reactors (Pérez et al.,

119 2000)or single-pass flow-through batch reactors (Gudavalli et al., 2013). An advantage of

120 dynamic over static experimental systems is the removal of reaction productsthat may influence

121 reaction rate or solubility of mineral phases (Handley-Sidhu et al., 2009). In flow-through tank or 
122 batch reactors, the ratio of solution volume to reactant solid is usually high in order to maintain

123 dilute conditions and allow solutions to access solid surfaces. Packed-column flow-through

124 experiments offer a different type of dynamic system that better simulates hydrologic conditions

125 representative of saturated subsurface environments. This experimental approach, however, has

126 the potential disadvantages of preferential flow paths, transport-limited rather than surface-

127 limited reactions, and non-uniform contact of the reactant solution with surfaces (Steefel and

128 Maher, 2009; Zhu, 2009). Column experiments have been used to study the release of $U$ from

129 contaminated soils and sediments under different environmental conditions (Eagling et al., 2013;

130 Liu et al., 2008; Qafoku et al., 2005). However, no studies have reported dissolution rates of

131 uranyl oxyhydroxide minerals under thermodynamically undersaturated and/ordynamic

132 conditions of flow within porous media to simulate subsurface conditions.

133 Developing a molecular-scale understanding of dissolution, desorption, and mineral 134 transformation processes in simplified systems is crucial for improving predictions of uranium 135 transport and fate in complex subsurface environments over time. The overall aim of this study 136 was to determine the dissolution rates and mechanisms of two uranyl oxyhydroxide end137 members (K- and Na-compreignacite) in a simulated porewater flow regime with different total 138 dissolved carbonate concentrations and $\mathrm{pH}$. Experimental solutions were chosen with relevance 139 to a site of uranium contamination, the Department of Energy's Hanford site (WA, USA), but the 140 solution compositionis also typical of freshwater aquifer systems. Solution and solid phases were 141 analyzed and characterized by chemical, microscopic, and spectroscopic techniques before and 142 after reaction to help establish dissolution mechanisms. To accurately account for the coupled 143 effects of reaction and transport on dissolution rate, solution effluent data from experimental 144 columns was used to parameterize a multicomponent reactive transport modelthat was then used 145 to determine optimized overall reaction rates and investigate the importance of changes in 146 mineral mass with time. This approach enables comparison of uranyl mineral dissolution rates 147 measured in static or batch-flow experiments with those in flow conditions relevant to $\mathrm{U}$ 148 mobilization in a porous medium. 


\section{MATERIAL AND METHODS}

\subsection{Synthesis of uranyl oxyhydroxide minerals}

Uranyl minerals were synthesized following a method adapted from Gorman-Lewis et al.(2008b). In a $23 \mathrm{~mL}$ Teflon-lined Parr bomb containing $5 \mathrm{~mL}$ of ultrapure water $(18.2 \mathrm{M} \Omega \cdot \mathrm{cm}$, EASYpure UV, Barnstead Thermolyne), $0.21 \mathrm{~g}$ of uranyl nitrate hexahydrated $\left(\mathrm{UO}_{2}\left(\mathrm{NO}_{3}\right)_{2} \cdot 6 \mathrm{H}_{2} \mathrm{O}\right.$; Spectrum Chemicals, USA) were reacted with $0.03 \mathrm{~g}$ of $\mathrm{K}_{2} \mathrm{CO}_{3}$ or $0.09 \mathrm{~g}$ of $\mathrm{NaHCO}_{3}$ to synthesize K-compreignacite and Na-compreignacite, respectively. The $\mathrm{pH}$ of the mixtures was adjusted to $\sim 5$ with $10-20 \mu \mathrm{L}$ of $15.7 \mathrm{M} \mathrm{HNO}_{3}$. The Parr bomb was uniformly heated at $100-105^{\circ} \mathrm{C}$ in a furnace for $24 \mathrm{~h}$. The dark yellow precipitates that formed were rinsed with hot(just below boiling) ultrapure water, vacuum filtered ( $0.45 \mu \mathrm{m}$ Metricel Membrane filters), and finally air dried. The syntheses were repeated several times until a total of 0.6-0.8 g of each mineral was attained. Reaction yields with respect to initial uranyl nitrate mass were $87.8 \%$ on average for both minerals. The air dried precipitates were homogenized and characterized (details in section 2.3) prior to preparation of flow-through columns.

\subsection{Dissolution flow-through column experiments}

Three sets of experiments were carried out in this work using a flow-through reactor design in which uranyl mineral species were mixed with quartz and packed into columns: i) dissolution of the two uranyl oxyhydroxide minerals with a representative background porewater solutions (BPW) of low dissolved carbonate (ca. $0.2 \mathrm{mmol} \mathrm{L}^{-1}$ ), ii) dissolution of the two minerals under the same BPW conditions but with higher total dissolved carbonate (ca. $2.8 \mathrm{mmol} \mathrm{L}^{-1}$ ), and iii) control columns with low and high carbonate BPW (with and without dissolved U(VI)), and without $\mathrm{U}$ minerals, to measure background concentrations and characterize uranyl sorption onto quartz during transport through the column. The three sets were prepared in the same manner as described below, and full experiment characteristics are summarized in Tables 1 and 2.

Synthesized uranyl minerals were mixed with cleaned quartz grains (200-400 $\mu \mathrm{m}$ size) as background filler to obtain a homogenous distribution within columns. Approximately $3.8 \mathrm{~g}$ of cleaned quartz (Unimin, Inc.; see S1 in SI for cleaning procedure) were combined with 0.06-0.40 g of K-compreignacite or Na-compreignacite. Mixtures were divided in two portions for duplicate, simultaneous column dissolution experiments, with a small fraction (0.05-0.10 g) used 
178 for total acid digestion of solids and elemental analysis by inductively coupled plasma mass 179 spectrometry (ICP-MS, section 2.3) to determine total U mass in each column.K- or Na180 compreignacite-quartz mixtures $(1.87 \pm 0.07 \mathrm{~g})$ were gently dry-packed into $1.0053 \mathrm{~cm}^{3}$ 181 volumepolypropylene Rezorian tubes (0.8 cm ID x 2 cm length; Sigma Aldrich)and capped with 182 polyethylene frits (20 $\mu \mathrm{m}$ pore size).Disposable syringe filters (0.2 $\mu \mathrm{m}$ pore size, 183 nylon; Whatman) were placed before and after the packed column material to avoid particleloss 184 out of the column. The exact mass introduced in each column was accurately recorded.

A total of eight columns with either K-compreignacite or Na-compreignacite were reacted at 186 187 room temperature and ambient atmospheric $\mathrm{CO}_{2}$ with continuous upward flow of a synthetic BPW solution containing either low or high total dissolved carbonate (Table 1) using a peristaltic pump and 2-stop PharMed BPT tubing (orange-blue, 0.25 mm ID; Cole-Parmer). The low carbonate BPW solution was representative of $\mathrm{NO}_{3}$-free Hanford porewater of $\mathrm{pH}$ 7.1-7.2

190 (Thompson et al., 2010). Carbonate salts were substituted for chloride salts to produce the high carbonate BPW solution (pH 8.0-8.2).Influent solution $\mathrm{pH}$ to the columns drifted slightly (0.15-

$1920.45 \mathrm{pH}$ units) from $\mathrm{pH}$ measured in reservoir bottles (especially in the unbuffered systems)likely 193 due to leaching of trace amounts of mineral oil or blend materialpresent in newPharMed BPT 194 tubing (www.masterflex.nl, (Malczewski and Inman Jr., 2007)). Table 1 reports the solution 195 pHreaching the columns after passing through the tubing. Replicates at low or high carbonate 196 concentration were run simultaneously for the durations and flow rates shown in Table 2.

197 Effluent solution samples were collected using a fraction collector (CF-2, Spectrum 198 Laboratories, Inc.) every $8 \mathrm{~min}$ ( 1 PV) for the first $160 \mathrm{~min}$, every $40 \mathrm{~min}$ ( 5 PV) from 160 to $199600 \mathrm{~min}$, and every $160 \mathrm{~min}$ ( 20 PV) for the rest of the run. Effluent samples were: i) diluted 200 with $2 \% \mathrm{HNO}_{3}$ for elemental analysis (U, Na, Ca, K and Mg) by ICP-MS, ii) diluted with 201 ultrapure water for anion determination by IC, and iii) measured undiluted for total dissolved 202 carbon by TC analysis (details in section 2.3). The pH was measured in 6-10 individual effluent 203 samples per column experiment. Two types of control columns (in duplicate) were prepared in 204 the same manner as described above with cleaned quartz but no uranyl minerals (Table 2), and 205 leached with low and high carbonate BPW input solutions(Table 1): i) containing no dissolved $206 \mathrm{U}(\mathrm{VI})$ and ii)containing $4 \mu \mathrm{mol} \mathrm{L}{ }^{-1}$ dissolved U(VI) (prepared from uranyl acetate salt; 207 Spectrum Chemicals, USA). After reaction, columns were disassembled, and the contents 
208 homogenized and air dried before storage. Solids were characterized before and after reaction by 209 methods described in section 2.3.

210 For all columns, the fluid or pore volume (PV), calculated from the total column volume 211 minus the volume of the solids (quartz and U-minerals), was between 0.2985 and $0.3451 \mathrm{~mL}$

212 (Table 2). Column porosityvalues, estimated from pore volume divided by total column volume, 213 were between 0.29 and 0.34 . Volumetric flow rate (Q) of the solution was calculated from the 214 weighed effluent volumes ( 0.035 to $0.038 \mathrm{~mL} \mathrm{~min}^{-1}$ in uranyl mineral columns, and 0.027 to $2150.044 \mathrm{~mL} \mathrm{~min}^{-1}$ in control columns; Table 2). A 40-min pulse of a conservative tracer solution 216 (BPW solution containing 0.5-1 mmol L ${ }^{-1} \mathrm{Br}$ ) was introduced at the beginning and end of each

217 dissolution experiment to determine column transport properties. Effluent solution samples were 218 collected every 8 min ( 1 PV) and Br concentration was determined by ICP-MS (details in 219 section 2.3). Representative fits to Br breakthrough curves are shown in the SI (Fig. S1). The 220 linear fluid velocity $\left(v, \mathrm{~cm} \mathrm{~min}^{-1}\right)$ and longitudinal dispersion coefficient $\left(\mathrm{D}_{\mathrm{L}}, \mathrm{cm}^{2} \mathrm{~min}^{-1}\right)$ values 221 (Table 2) were obtained by fitting the Br breakthrough curves to an advection-dispersion finite222 length pulse source model (Runkel, 1996). Dispersivity $\left(\alpha_{\mathrm{L}}, \mathrm{cm}\right)$ was calculated as $\alpha_{\mathrm{L}}=$ $223 \mathrm{D}_{\mathrm{L}} / v$ (Table 2). Transport properties from $\mathrm{Br}$ tracer fits showed differences of less than $5 \%$ 224 between the beginning and the end of each experiment.

\section{$225 \quad 2.3$ Analytical and spectroscopic techniques}

\section{2.3.1Solidphase characterization}

227 Synthesized uranyl minerals were characterized by the methods described below. Column 228 mixtures before and after reaction with BPW solutions were characterized by SEM imaging, 229 specific surface area measurements, and acid digestion and total element analyses.

$230 X$-ray diffraction $(X R D)$. Samples were mounted on zero-background Si holders and scanned 231 from 4 to 80 degrees $2 \theta$ (0.01steps) using a Philips X'Pert MPD diffractometer and an ultra-fast

232 X'Celerator detector (Ni-filtered Co K- $\alpha$ source, $\lambda=1.78 \AA$, $50 \mathrm{kV}, 40 \mathrm{~mA}$ ). XRD patterns were 233 analyzed with X'Pert HighScore Plus software using its internal library reference spectra (ICDD 234 Powder Diffraction File (1998)). The detection limit of the analysis is 2-3\% wt. 
236 (DeltaNu, Laramie, WY) Raman module equipped with a $785 \mathrm{~nm}, 120 \mathrm{~mW}$ laser excitation 237 source, a CCD detector ( $0.5 \mathrm{~cm}^{-1}$ resolution) and an Olympus BX51 microscope (50x objective, 2380.75 numerical aperture) was used to collect the Raman spectraon single crystals(30 s integration 239 time),and to confirm uranyl bonds and hydration of the minerals. No corrections were performed 240 on the measured spectra. FT-IR reflectance spectra (25 per sample) were acquired on a Bruker, 241 Alpha-P infrared reflectance spectrometer. Solid samples were directly loaded in the diamond 242 window. Spectra were averaged for each sample using the OPUS/Mentor Operating software.

243 SEM and thermogravimetric analyses (TGA).Air-dried particles of the minerals were imaged 244 using a FEI Quanta 200 environmental scanning electron microscope (ESEM) with a tungsten 245 filament. Images were obtained at high vacuum ( $<10^{-4}$ Torr), $20 \mathrm{kV}$ voltage and 90-100 $\mu \mathrm{A}$ 246 emission current. The water content of the uranyl minerals was determined by TGA by heating

$247 \sim 20 \mathrm{mg}$ of air-dried mineral powder from room temperature to $600^{\circ} \mathrm{C}$ at $10^{\circ} \mathrm{C} \mathrm{min}^{-1}$ in an $\mathrm{Ar}$ 248 purge (2000 $\left.\mathrm{mL} \mathrm{min}^{-1}\right)$ using a Seiko model TGA/DTA 320. Number of water molecules 249 (hydration and structural water) was calculated from the weight lossat the temperature range 20$250400^{\circ} \mathrm{C}$.

251 Particle size and surface area.Particle size distribution of an aliquot of dried mineral suspended 252 in ultrapure water was measured at a wavelength of $633 \mathrm{~nm}$ and $45^{\circ}$ angle for 2 min using 253 Dynamic Laser Scattering (DLS, Brookhaven Instruments BI-9000AT).Specific surface area 254 (SSA) was determined on dried samples by the $\mathrm{N}_{2}$-BET method (Brunauer-Emmett-Teller 255 (BET)) using a surface area analyzer (Tri-Star 3000, Micrometrics).

256 Elemental analysis of solids. Microwave acid digestion $\left(40 \mathrm{~min}, 160^{\circ} \mathrm{C}, 18 \mathrm{bar}\right.$; Anton Paar 257 Multiwave 3000)was carriedout in duplicate by adding $9 \mathrm{~mL} \mathrm{HCl}$ and $3 \mathrm{~mL} \mathrm{HNO}_{3}$ to $0.04-0.06 \mathrm{~g}$ 258 of air-dried samples. The digests were subsequently diluted with ultrapure water to a final $1-5 \%$ $259 \mathrm{HNO}_{3} \mathrm{v} / \mathrm{v}$ concentration forICP-MS analysis.

\subsubsection{Solution chemical analysis}

261 Dissolved U, Na, Ca, K, Mg and Br concentrations from effluent solutions and acid digests 262 were measured using inductively couple plasma-mass spectrometry (ICP-MS, Agilent 7500ce 263 Cetac - ASX-510 Autosampler). Samples and standards were analyzed in $2 \% \mathrm{HNO}_{3}$ matrix and 
264 the latter were freshly prepared from $1000 \mu \mathrm{g} \mathrm{mL}^{-1} \mathrm{ICP}$ standard solutions obtained from GFS 265 Chemicals, Inorganic Ventures and Fluka Chemicals. Blank and check standard solutions were analyzed every 10-12 samples to account for any signal drift. Method detection limits were $10 \mathrm{pg}$ $\mathrm{L}^{-1}$ for $\mathrm{U}$ and $10-25 \mu \mathrm{g} \mathrm{L}{ }^{-1}$ for $\mathrm{Na}, \mathrm{K}, \mathrm{Ca}, \mathrm{Mg}$ and $\mathrm{Br}$; the repeatability of the analyses, as relative standard deviation (RSD), was always $\leq 2 \%$ for all elements.

The concentration of anions $\left(\mathrm{Cl}^{-}, \mathrm{SO}_{4}{ }^{2-}\right)$ in the effluent solutions was determined by ion chromatography (IC) using a Dionex ICS-2000 chromatography system (AS18 chromatographic column) with suppressed conductivity detection. Total dissolved carbon (TC) concentration was

272 analyzed from undiluted effluent solutions using a Shimadzu TOC-Vcsh Total Organic Carbon

273 Analyzer coupled with an ASI 5000A autosampler. IC and TOC systems were daily calibrated 274 with standard solutions freshly prepared from $1000 \mu \mathrm{g} \mathrm{mL}^{-1}$ seven anion IC aqueous standard

275 (Dionex) and potassium hydrogen phthalate $\left(\mathrm{C}_{6} \mathrm{H}_{4}(\mathrm{COOK})(\mathrm{COOH})\right)$ stock solution, respectively. 276 Standard checks and blanks were run every 10-15 samples to account for signal drift. The limit

277 of detection was $10-25 \mu \mathrm{g} \mathrm{L}^{-1}$ for both anions and $50 \mu \mathrm{g} \mathrm{L}^{-1}$ for dissolved TC. Both analytical 278 techniques present a RSD of $<3 \%$ on their measurements.

\subsubsection{X-ray absorption spectroscopy (XAS)}

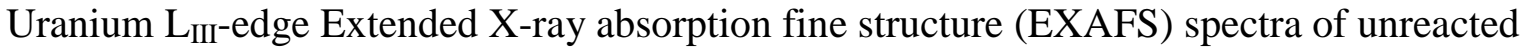
minerals and reacted column mixtures were collected on beamlines 4-1 and 11-2 at the Stanford 282 Synchrotron Radiation Lightsource (SSRL) under dedicated conditions (current 500 mA). Air283 dried K-compreignacite and Na-compreignacite (synthesized minerals) were diluted with sucrose 284 (1:4 ratio) to achieve a maximum log absorbance $\left(\mathrm{I}_{0} / \mathrm{I}_{\mathrm{t}}\right)$ around 1 in transmission mode. For data collection in fluorescence mode, reacted column mixtures(containing quartz and synthesized uranyl minerals) were ground manually and diluted with sucrose to 2000 ppm U; reacted control columns (containing only quartz with sorbed U) were ground but not diluted. Samples were loaded in aluminum holders, sealed with Kapton tape and held in a liquid nitrogen cryostat to maintain low vacuum and temperature ( $\sim 77 \mathrm{~K})$. Samples were measured using a $\mathrm{Si}(220)$ monochromator crystal with the second crystal detuned $20-30 \%$ at $17,600 \mathrm{eV}$ to reject harmonic reflections. Beam size on the sample was 1 x 4-7 mm and XAS data was collected with either a

293 standard with the first inflection on the absorption edge set to 17,038 eV. 
Three to twelve scans were collected for each sample and averaged using SIXpack (Webb, 2005). The ATHENA and ARTEMIS software package (Ravel and Newville, 2005) was used for background subtraction, normalization, and EXAFS fits. Background was subtracted by a linear fit through the pre-edge region and a spline fit through the EXAFS region $\left(\mathrm{k}=0 \AA^{-1}\right.$ was set to 298 17,185 eV) using Autoback in ATHENA, and spectra were normalized to the post-edge step height. Non-linear least-squares shell-by-shell EXAFS fits ( $\mathrm{k}^{3}$-weighing, $\mathrm{k}$ range $=2$ to 13.514.5 $\AA^{-1}$, R-range $=1.1-7 \AA$ ) were carried out using ARTEMIS on the unreacted minerals to verify the local bonding environment of $\mathrm{U}(\mathrm{VI})$ compared to published crystal structure analysis. The crystallographic interatomic distances reported in Burns (1998) for K-compreignacite were used as the initial model for calculation of K- and Na-compreignacite theoretical EXAFS spectra 304 for shell-by-shell fits (no structure determination was found for Na-compreignacite).Groups of backscattering atoms at similar interatomic distances were determined by trial-and-error fitting based on this ideal crystal structure. The amplitude reduction factor $\left(\mathrm{S}_{0}{ }^{2}\right)$ was set to 1 and energy shift $\left(\Delta \mathrm{E}_{0}\right)$ was linked as a single parameter for all shells. For uranyl bonded to 2 axial oxygen atoms (U-Oax), coordination number (N) was fixed at 2 for single scattering (SS) and 4 for multiple scattering (MS), distance (R)was constrained to double the SS distance, and DebyeWaller factors $\left(\sigma^{2}\right)$ wereallowed to vary. For all other shells, $\mathrm{N}$ was fixed on the weighted average of all $\mathrm{U}$ environments in the crystal structure for a given shell, and $\sigma^{2}$ and $\mathrm{R}$ varied.

The EXAFS spectra of reacted columns were analyzed by both least-squares linear combinations of uranyl reference compound spectra and shell-by-shell fits with theoretical

314 standards to identify changes in the U(VI) bonding environment. Reference compounds included 315 uranyl oxyhydroxides (K-compreignacite, Na-compreignacite, becquerelite, schoepite), uranyl 316 nitrate, and uranyl sorbed on quartz (reference spectra from this work and Kanematsu et al. 317 (2014)). Component weights of the reference spectra were constrained between 0 and 1 in linear 318 combination fits but not forced to sum to unity. Components with a fraction of less than $10 \%$ in 319 the fit were removed as they did not significantly improve fit statistics. Spectra were fit as 320 described above for shell-by-shell analysis ( $\mathrm{k}$-weight $=3$; $\mathrm{k}$-range $=2$ to $13.0-14.0 \AA^{-1}$; R-range $321=1.1-7 \AA$ ) except that $\sigma^{2}$ was fixed to the value or average value obtained in fits to reference 322 spectra for a given backscattering atom, and $\mathrm{R}$ and $\mathrm{N}$ were allowed to vary. 


\subsection{Dissolution rates and reactive transport modeling}

Reactive transport (RT) calculations of column experiments were carried out using the code CrunchFlow (Steefel et al., 2015). This RT code considers all solid-aqueous phase reactions to be kinetic, and uses rate laws and coefficients included in the database in addition to thermodynamic solubility constants. Thermodynamic constants were obtained from available databases and the literature. Table S3 in SI gives the principal chemical equilibria and surface adsorption reactions considered in this study. To our knowledge, there are no published dissolution rates or constants for uranyl oxyhydroxide minerals. Therefore, CrunchFlow was used in conjunction with the present experimental data set to calculate rates for uranyl mineral dissolution and release of $\mathrm{U}$ under flow conditions.

CrunchFlow operates by running multiple parallel reaction pathways affecting the same solid phase and using a specified type of mineral dissolution or precipitation rate law (Steefel et al., 2015). In this work, the transition state theory (TST) rate law was selected for RT simulations to include the thermodynamic mineral solubility of the overall dissolution reaction andthe mineral surface area (Steefel et al., 2015).The general rate law formulation (linear or nonlinear) for TST-type precipitation or dissolution reactions $\left(\mathrm{R}_{\mathrm{m}}, \mathrm{mol} \mathrm{m} \mathrm{m}^{-3}\right.$ porous medium s$\left.{ }^{-1}\right)$ takes into account the reactive surface area of a mineral $m\left(\mathrm{~A}_{\mathrm{m}}, \mathrm{m}^{2}\right.$ mineral $\mathrm{m}^{-3}$ porous media), arate constant $\left(\mathrm{k}_{\mathrm{m}}, \mathrm{mol} \mathrm{m} \mathrm{m}^{-2} \mathrm{~s}^{-1}\right)$, a product term for reaction catalysis or inhibition $\left(\Pi a^{n}\right)$, and a term for thermodynamic affinity, which includes the ion activity product for the mineral-water reaction

$342\left(\mathrm{Q}_{\mathrm{m}}\right)$, and the corresponding thermodynamic equilibrium constant $\left(\mathrm{K}_{\mathrm{eq}}\right)$ (positive for precipitation, negative for dissolution):

$$
\begin{aligned}
& \mathrm{R}_{\mathrm{m}}=\mathrm{A}_{\mathrm{m}} \mathrm{k}_{\mathrm{m}} \prod a^{n}\left[\left(\frac{\mathrm{Q}_{\mathrm{m}}}{\mathrm{K}_{\mathrm{eq}}}\right)^{\eta}-1\right]^{m} \text { when } \log \left(\mathrm{Q}_{\mathrm{m}} / \mathrm{K}_{\mathrm{eq}}\right)>0 \\
& \mathrm{R}_{\mathrm{m}}=-\mathrm{A}_{\mathrm{m}} \mathrm{k}_{\mathrm{m}} \prod a^{n}\left[\left(\frac{\mathrm{Q}_{\mathrm{m}}}{\mathrm{K}_{\mathrm{eq}}}\right)^{\eta}-1\right]^{m} \text { when } \log \left(\mathrm{Q}_{\mathrm{m}} / \mathrm{K}_{\mathrm{eq}}\right)<0
\end{aligned}
$$

The catalysis or inhibition term $\left(\Pi a^{n}\right)$ is the product of all far from equilibrium effects by various species in solution on the reaction (such as $\mathrm{pH}$ ), with $n$ as the reaction order, and mand $\eta$ are experimentally or theoretical determined exponential dependences (see details in Steefel et al. (2015)). In this study, no dependence on the concentration of solution species was used (i.e., variablesin the term $\Pi a^{n}$ were not included). Since column experimentalconditions were 
349 undersaturated with respect to uranyl mineral solubility (see section 4.1), the contribution of the 350 thermodynamic affinity term isinsignificant; hence, the TST rate law (Eq. 1) is a function of only $351 \quad A_{m}$ and $k_{m}$. Under these conditions, the rate constant $\left(k_{m}\right)$ becomes equivalent to a surface area 352 normalized rate, $\mathrm{R}_{\mathrm{s}}$ in $\mathrm{mol} \mathrm{m}^{-2} \mathrm{~s}^{-1}$ (Eq. 2) applied to a congruent, overall mineral dissolution 353 reaction:

$$
\mathrm{R}_{\mathrm{s}}=\mathrm{k}_{\mathrm{m}}=-\frac{\mathrm{R}_{\mathrm{m}}}{\mathrm{A}_{\mathrm{m}}}
$$

354 In our RT simulations, measurements of specific surface area $\left(\mathrm{A}_{\mathrm{s}}, \mathrm{m}^{2} \mathrm{~g}^{-1}\right)$ by the $\mathrm{N}_{2}$-BET 355 method ( $\mathrm{N}_{2}$-BET SSA in Table 3 ) and the measured mass of uranyl mineral loaded into the 356 column (Table 2) were used to calculate the initial $\mathrm{A}_{\mathrm{m}}$ following Eq.3:

$$
\mathrm{A}_{\mathrm{m}}=\frac{\mathrm{A}_{\mathrm{s}} \cdot \phi_{\mathrm{m}} \cdot \mathrm{MW}}{\mathrm{V}_{\mathrm{m}}}
$$

357 where $\phi_{\mathrm{m}}$ is the volume fraction ( $\mathrm{m}^{3}$ mineral $\mathrm{m}^{-3}$ total volume), $\mathrm{MW}_{\mathrm{m}}$ is the molecular weight ( $\mathrm{g}$ $\left.358 \mathrm{~mol}^{-1}\right)$, and $\mathrm{V}_{\mathrm{m}}$ is the molar volume $\left(\mathrm{m}^{3} \mathrm{~mol}^{-1}\right)$ of the mineral phasem. Since changes in $\mathrm{A}_{\mathrm{s}} \mathrm{of} \mathrm{a}$ 359 specific dissolving mineral in a porous medium over the course of an experiment are unknown, 360 changes in particle size (and thus reactive surface area, $A_{m}$ ) with dissolution were examined 361 through changes in the mineral volume fraction $\left(\phi_{\mathrm{m}}\right)$ and total porosity, $\phi$ (Eq. 4$)$ :

$$
\phi=1-\sum_{m=1}^{N_{m}} \phi_{m}
$$

362 Initial column porosityand $\phi_{\mathrm{m}}$ of uranyl minerals and quartz were calculated from the initial 363 mineral mass and volume packed in the column (Table 2).The code was set to update column 364 porosityat each time stepas a result of mineral mass dissolved and transferred from the solid 365 phase to the aqueous phase. The linear fluid velocity (or pore velocity, $v$ ) obtained from fitting 366 Br tracer breakthrough curves (Table 2, Fig. S1 in SI)was set as a constant in the RT model, but 367 the update of porosity $(\phi)$ was allowed to change the volumetric flux (or Darcy flux), $q\left(\mathrm{~m}^{3} \mathrm{~m}^{-2}\right.$ 368 medium s ${ }^{-1}$ ), according to Eq. 5(Lichtner, 1997):

$$
q=\phi \cdot v
$$


These flow and mineral parameters are considered in the mass conservation equation for the transport of solute species in a multicomponent porous medium used by CrunchFlow, which describes the evolution of total concentration of the solute $i, \Psi_{\mathrm{i}}$, as a function of timefollowing

372 thegoverningdifferential equation(Lichtner, 1997; Steefel et al., 2015):

$$
\frac{\partial\left(\phi \Psi_{\mathrm{i}}\right)}{\partial \mathrm{t}}=\nabla\left(\phi \mathrm{D}^{*} \nabla \Psi_{\mathrm{i}}\right)-\nabla\left(\mathrm{q} \Psi_{\mathrm{i}}\right)-\sum_{\mathrm{m}=1}^{\mathrm{N}_{\mathrm{m}}} \mathrm{v}_{\mathrm{im}} \mathrm{R}_{\mathrm{m}}
$$

373 where the first two divergence operators $(\nabla)$ involving porosity, $\phi$, the dispersion-diffusion 374 coefficient, $\mathrm{D}^{*}$, and volumetric flux, $q$, are terms related to the transport through the porous 375 medium, and the last reaction term includes the number of moles of iin each mineral $m\left(v_{\mathrm{im}}\right)$ and the TST mineral dissolution/precipitation rate, $\mathrm{R}_{\mathrm{m}}$.

Therefore, surface area normalized rates $\left(\mathrm{R}_{\mathrm{s}}\right)$ of $\mathrm{K}$ - and Na-compreignacite in low and high carbonate BPW flow-through conditions were calculated by numerical optimization using a Model-Independent Parameter Estimation and Uncertainty Analysis (PEST) (Doherty, 2015) implemented in CrunchFlowto fit the experimental total U concentration in the effluent solution ([U] $]_{\text {tot }}$, mol L ${ }^{-1}$, as $\Psi_{\mathrm{i}}$ in Eq.6) over time. Two approaches were followed: i) optimization of the rate constant, $\mathrm{k}_{\mathrm{m}}$, using a fixed uranyl mineral volume fraction $\left(\phi_{\mathrm{m}}\right)$ calculated from initial mineral mass (method RT-TST); and ii) optimization of $\mathrm{k}_{\mathrm{m}}$ and $\phi_{\mathrm{m}}$ simultaneously, with the maximum $\phi_{\mathrm{m}}$ set to thatcalculated from initial mineral masses (method RT-TST-VF).Note that the initial $\phi_{\mathrm{m}}$ of uranyl mineral was $2.8-4.4 \%$ of total column volume for low carbonate BPW 386 experiments and less than 1\% of column volume in high carbonate BPW experiments (Table 387 2).For both RT calculations, the physical properties of the columns and their transport characteristics (Table 2) were obtained from fitting $\mathrm{Br}$ tracer breakthrough curves as described in

389 section 2.2. Mineral volume fractions (from masses), specific surface areas, and BPW solution 390 compositions were used in the simulations (Table 1, 2 and 3), with control columns used to 391 check validity of flow parameters. To assess sorption of dissolved uranyl on quartz, control 392 columns reacted with low carbonate BPW containing dissolved U(VI) were used to estimate $393 \mathrm{U}(\mathrm{VI})$ surface complexation equilibrium constants (details in S5, Table S4 and Fig. S6 in SI). 394 These constantswere subsequently appliedin the RT simulations of uranyl mineral dissolution. 
Other authors studying mineral dissolution in flow conditions calculated dissolution rates when the system reached steady-state dissolution conditions, i.e. $\mathrm{d}[\mathrm{U}] / \mathrm{dt}=0$, with the assumption that the solution is sufficiently undersaturated with respect to thermodynamic mineral solubility. In that case, the overall rate can be derived from a mass balance as presented in Ulrich et al. (2008). The equation takes the form:

$$
\mathrm{R}_{\mathrm{n}}=\frac{\mathrm{Q} \cdot[\mathrm{U}]}{\mathrm{V} \cdot \mathrm{A}_{\mathrm{s}} \cdot[\text { solid }]}
$$

400 where $R_{n}$ is the dissolution rate at steady-state $\left(\mathrm{mol} \mathrm{m}^{-2} \mathrm{~s}^{-1}\right), \mathrm{Q}$ is the volumetric flow rate $\left(\mathrm{mL} \mathrm{s}^{-1}\right)$,

$401[\mathrm{U}]$ is steady-state effluent concentration $\left(\mathrm{mol} \mathrm{L}^{-1}\right), \mathrm{V}$ is the fluid volume within the column 402 (mL), $A_{s}$ is the specific surface area $\left(\mathrm{m}^{2} \mathrm{~g}^{-1}\right)$ and [solid] is the mass concentration of $U$ in the 403 column (g solid L $\mathrm{L}^{-1}$ fluid). Similar rate equations were used for flow reactor experiments in Pérez 404 et al. (2000) and Gudavalli et al. (2013), but without considering the mass in the reactor or the 405 decrease of particle size and solid concentration as the mineral dissolved. Here, Eq. 7 was used 406 to calculate K- and Na-compreignacite dissolution rates for each duplicated mineral column 407 using U effluent concentration once an apparent steady-state was reached. In this steady-state 408 dissolution approach (method SSD), the specific surface area and mass concentration of U were 409 not updated with dissolution. Calculated $\mathrm{R}_{\mathrm{n}}$ rates were averaged for each mineral and each BPW 410 condition (between 6 and 14 data points). These calculations allow comparison of steady-state 411 and RT methods for calculating overall dissolution rates as $\mathrm{R}_{\mathrm{s}}$ (surface area normalized rate).

\section{3. RESULTS}

\section{$413 \quad 3.1$ Flow-through columnexperiments}

\subsubsection{Control columns}

415 Quartz columns with no uranyl solid were reacted with low and high carbonate BPW 416 without (Control1) and with U(VI) in solution (Control2) (Fig.1). In the low carbonate systems, 417 influent $\mathrm{U}$ was retarded for the first $\sim 200 \mathrm{PV}$ and reached input concentration after $\sim 800 \mathrm{PV}$. An 418 estimated average of $1.55 \cdot 10^{-7} \mathrm{U} \mathrm{mol} \mathrm{g}^{-1}$ quartz was retained in the columns after reaction based 419 on U mass introduced in the column and integrated effluent concentrations. In contrast, the high 420 carbonate systems showed no $U$ retardation and $U$ effluent reached input concentrations within 421 the first $20 \mathrm{PV}$ (150 min).Effluent $\mathrm{pH}$ in low carbonate systems slightly decreased from $\mathrm{pH}$ 6.95- 
4227.00 in input solutions to an average of $\mathrm{pH}$ 6.93, and the total dissolved carbon (TC)

423 concentrations were within error of the input solutions $\left(0.34 \pm 0.04 \mathrm{mmol} \mathrm{L}^{-1} \mathrm{TC}\right)$. In the high

424 carbonate experiments both values stabilized to the input solution (ca. pH 7.80 and $2.2 \mathrm{mmol} \mathrm{L}^{-}$

$425{ }^{1}$ TC) by 200 PV. For both controls, effluent concentrations of non-uranyl components, i.e., 426 cation and anion concentrations, were not detectably altered from input solution concentrations 427 (data shown in SI, Fig. S2).

\section{3.1.2 Low carbonate BPW experiments}

429 Effluent concentrations of $\mathrm{U}$, cations, anions, total carbon and $\mathrm{pH}$ relative to input solution 430 concentrations for K- and Na-compreignacite with low carbonate BPW columns are shown in 431 Fig. 2. In the first $200 \mathrm{PV}$, a pronounced U release was observed for both minerals, with a higher 432 pulsed released in the case of K-compreignacite (maximum of $50 \mu \mathrm{mol} \mathrm{L}^{-1} \mathrm{U}$ at $60 \mathrm{PV}$ ), and by $433800 \mathrm{PV}$ an apparent steady-state was reached $\left(\sim 3 \mu \mathrm{mol} \mathrm{L}{ }^{-1} \mathrm{U}\right)$. Over the entire experiment, total $434 \mathrm{U}$ removed from the columns was only $0.5 \%$ of the initial U mass (Table 2). Similar to U, K 435 from K-compreignacite and Na from Na-compreignacite were initially flushed from the columns 436 and reached a steady effluent concentration after $\sim 200 \mathrm{PV}$. In Na-compreignacite columns, K 437 from the input solution was strongly retained within the column as evidenced by the failure to 438 reach steady-state after $1400 \mathrm{PV}$. In K-compreignacite columns, K-effluent reached influent 439 concentrations after $\sim 200 \mathrm{PV}$, but then slightly decreased at $800 \mathrm{PV}$. However, there was no 440 apparent uptake of $\mathrm{Na}$ from the input solution in the K-compreignacite columns. For both 441 minerals, Mg and Ca reached steady-state within the first 25 and $100 \mathrm{PV}$, respectively, without a 442 significant retardation in the column. Anions $\left(\mathrm{Cl}^{-}\right.$and $\left.\mathrm{SO}_{4}{ }^{2-}\right)$ were also not retarded in the 443 columns. The effluent $\mathrm{pH}$ of all columns stabilizedafter $500 \mathrm{PV}$ to input solutionpH of 6.65.

444 Effluent TC concentrations of K-compreignacite columns presented some scatter between 445 duplicates andwith higher concentration than input solutions until ca. 800 PV.Na-compreignacite 446 duplicated columnsresulted in more consistent TC concentrations thatstabilized to influent 447 concentration $\left(0.21 \mathrm{mmol} \mathrm{L}^{-1}\right)$ after $100 \mathrm{PV}$.

\section{$448 \quad$ 3.1.3 High carbonate BPW experiments}

449 Increasing total carbonate concentration in the BPW greatly enhanced the dissolution of K450 and Na-compreignacite (Fig. 3) compared to the low carbonate systems. The concentration of 
451 dissolved $U$ reached a maximum of $\sim 500 \mu \mathrm{mol} \mathrm{L}^{-1}$ and thetotal amount of $U$ released from the 452 column corresponded to $\sim 60 \%$ of the initial U mass present for three of the four replicate 453 columns (Table 2). At the end of the experiments after $1400 \mathrm{PV}$, effluent U concentrations still 454 did not attain steady-state for either mineral. Similar to the low carbonate systems, the initial U 455 release was associatedwitha high release of K in the first $200 \mathrm{PV}$, which decreased steadily 456 throughout the experiment and only reached input solution (steady-state) concentrations in the 457 last 200 PV. Higher Na concentrations in the input solution showed more variability in the 458 effluent data and masked the evolution of Na release in Na-compreignacite columns, yet a slight 459 decreasing concentration trend over time can be observed. Potassium (K) present in the 460 influentwas notretained significantlyin these columnsin contrast to the low carbonate columns, 461 although it showed a slower increase(ca. 150 PV) towards the input solution concentration than 462 the divalent cations ( $\mathrm{Ca}$ and $\mathrm{Mg})$ and anions $\left(\mathrm{Cl}^{-}, \mathrm{SO}_{4}{ }^{2-}\right)$ which did not undergo a significant 463 retention and reached input solution concentrations in the first few PV. For both minerals, the 464 effluent TC started slightly higher than input solution concentration but reached influent values 465 after $100 \mathrm{PV}$, followed, only in the Na-compreignacite columns, by a small increase over time. 466 From the first few PV, effluent $\mathrm{pH}$ for both minerals was about one $\mathrm{pH}$ unit lower than the 467 influent solution and increased gradually over time. Na-compreignacite column effluenthad 468 higher $\mathrm{pH}$ than K-compreignacite systems and approached the influent pH of 8.40after $1100 \mathrm{PV}$.

\subsection{Mineral phase transformations}

\subsubsection{Structure and properties of synthesized K-and Na-compreignacite}

For the unreacted minerals, TGA analysis indicated6.60 and 7.29\% mass loss from K- and 472 Na-compreignacite, respectively (Table 3), which corresponds to 7.5-8 watermolecules.This is 473 higher than the estimated structural water ( $\mathrm{n}=7$ ) (Burns, 1998; Burns et al., 2004), but still 474 within 1\% permissible error of the TGA measurement. A ratio of $2.13 \pm 0.05 \mathrm{U}: \mathrm{K}$ and $3.78 \pm$ $4750.05 \mathrm{U}:$ Na were determined by elemental analysis for K- and Na-compreignacite, respectively, 476 compared with the expected stoichiometric ratio of 3 for the pure phase (Table 3). $\mathrm{N}_{2}$-BET 477 surface area was higher for K-compreignacite $\left(9.64 \pm 0.52 \mathrm{~m}^{2} \mathrm{~g}^{-1}\right)$ than for Na-compreignacite $478\left(3.53 \pm 1.80 \mathrm{~m}^{2} \mathrm{~g}^{-1}\right)$. X-ray diffractograms of $\mathrm{K}$ - and Na-compreignacite matched the primary 479 reflections of reference minerals well (Fig. 4 A1-A2), but lower peak intensity and line 480 broadening were observed in the samples. In both $\mathrm{K}$ - and Na-compreignacite FTIR spectra, 
481 bands around $920 \mathrm{~cm}^{-1}$ and at 2900-3600 $\mathrm{cm}^{-1}$ were observed (Fig. $4 \mathrm{~B}$ ) that correspond, 482 respectively, to the stretching vibrations of uranyl-oxygen bonds and to hydroxyl groups from 483 surface adsorbed water, structurally incorporated water or $\mathrm{OH}$. The K-compreignacite spectrum 484 also had a sharp peak at $1630 \mathrm{~cm}^{-1}$ corresponding to structurally incorporated water. In the Na485 compreignacite spectrum, this band was broad and less intense, probably due only to surface 486 adsorbed water. Both Raman spectra (Fig. 4 C) presented a very intense, sharp peak at $\sim 830 \mathrm{~cm}^{-}$ 487 , which corresponds to the symmetric stretching of the uranyl U-O bonds. The peaks at $~ 325$ 488 and $\sim 250 \mathrm{~cm}^{-1}$ can be assigned to the U-O ligand vibration, and to the uranyl bending and lattice 489 vibrations, respectively. Particle size analysis (Fig. 4 D1-D2) showed a similar distribution for 490 both minerals, with a main population at 80-300 nm and a second group at 975-2700 $\mathrm{nm}$ for K491 compreignacite and 425-1300 nm for Na-compreignacite. The smaller size fraction was more 492 abundant in K-compreignacite than Na-compreignacite. SEM images of both minerals (Fig. 5 B493 C) showed 50-200 $\mu \mathrm{m}$ agglomerations of particles smaller than $10 \mu \mathrm{m}$ with flakey and needle494 shape morphology. Similar particle shapes were observed by Sandino and Grambow (1994) for 495 K-compreignacite.

496 The EXAFS spectrum of unreacted K-compreignacite was fit shell-by-shell starting with the 497 crystal structure refinement reported in the literature (Table 4, Fig. 6 A). Equatorial oxygens

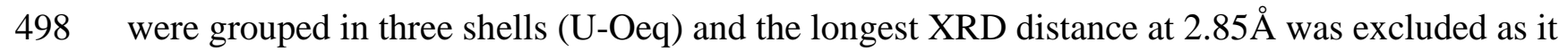
499 did not contribute significantly to the fit. The first U-U shells were grouped in two interatomic 500 distances, withthe shortest oneconverging to a distance shorter than reported by XRD ( 3.70 501 Åvs. $3.82 \AA$ from structure refinement). For the unreacted Na-compreignacite EXAFS spectrum 502 (Table 4, Fig. 6 B),U-Oeq distances were distributed in 3 shells with similar distances to K503 compreignacite, whereas thefirst U-U shells were grouped in fittingat $3.89 \AA$, resembling the 504 EXAFS fit to the becquerelite structure (Table 4, Fig. 6 C). In the becquerelite structure, the five 505 equatorial oxygen shells are grouped in just two distances at 2.26 and $2.47 \AA$, instead of three 506 distances as seen in the K- and Na-compreignacite fits. Control columns reacted withlow 507 carbonate BPW containing aqueous uranyl provided a reference spectrum of dissolved U(VI) 508 sorbed on quartz (Fig. 6 D) (the amount of U sorption on quartzwastoo low in high carbonate 509 BPW columns to collect EXAFS spectra). The optimum shell-by-shell fit (Table 4) was obtained 510 by grouping U-Oeq shells at distances similar to those reported in the literature for sorbed 511 aqueous uranyl on silica ( $\mathrm{R}=2.28$ and $2.48 \AA$ )(Batuk et al., 2011; Sylwester et al., 2000) and 
512 varying $\mathrm{N}$ with $\sigma^{2}$ fixed on average values determined from fits to crystalline reference

513 compounds.This EXAFS modelinformed the stoichiometrychosen for the two uranyl surface

514 complexation reactions and estimation of their sorption constants in RT simulations (section S5

515 and Table S4 in SI).

\subsubsection{Column materials before and after dissolution reactions}

Electron microscopyimages of the quartz control columns (Fig. 5 A1-A3) showed clean particles before and after reaction with low and high carbonate BPW solutions. When quartz was mixed with K- and Na-compreignacite, quartz particles were completely covered by the uranyl minerals (Fig. 5 B1 and C1). After reaction with low carbonate BPW, loose uranyl mineral grains were less abundant, but quartz grains were still covered with particles (Fig. 5 B2 and C2).

522 After reaction with high carbonate BPW, SEM images showed a much lower density of uranyl mineral particles on the quartz grains. K-compreignacite particles on quartz (Fig. 5 B3) had a

524 flaky morphology similar to the unreacted mineral, whereas Na-compreignacite particles (Fig. 5 525 C3) showed a more spherical shape after reaction.

Specific surface area (SSA) was measured on the quartz-uranyl mineral mixtures before and after reaction (Table 3). Quartz controls did not show significant variations after reaction, with SSA values averaging $0.125 \pm 0.008 \mathrm{~m}^{2} \mathrm{~g}^{-1}$. When the quartz was mixed with $\mathrm{K}$ - and $\mathrm{Na}$ compreignacite, the mixture's SSA increased slightly from quartz-only to 0.196 and $0.291 \mathrm{~m}^{2} \mathrm{~g}$ -

$530{ }^{1}$, respectively. After reaction with low carbonate BPW, the SSA of K-compreignacite column mixtures increased to $0.351 \mathrm{~m}^{2} \mathrm{~g}^{-1}$, while Na-compreignacite remained similar to unreacted

532 values. After reaction with high carbonate BPW, measured SSA was similar to that of quartz533 only control columns ( 0.122 and $0.104 \mathrm{~m}^{2} \mathrm{~g}^{-1}$ for K- and Na-compreignacite, respectively).

$534 \quad$ Acid digestion and total element analysis of K-compreignacite and quartz mixtures before and after reaction with low carbonate BPW showed a decrease in K concentration after reaction

536 (from 125 to $29 \mu \mathrm{mol} \mathrm{g}^{-1}$ ), resulting in a U:cation ratio of 2.64 compared with 2.03 before 537 reaction (Table 3). In high carbonate BPW experiments, U concentration decreased from 252 to

$53876 \mu \mathrm{mol} \mathrm{g}^{-1}$ and $\mathrm{K}$ concentration was decreased even further to $6.6 \mu \mathrm{mol} \mathrm{g}^{-1}$. For Na539 compreignacite columns, the Na concentration decreased from 51 to $18 \mu \mathrm{mol} \mathrm{g}^{-1}$ in low 540 carbonate BPW columns, although U concentration did not vary within measurement error (ca. 
$541200 \mu \mathrm{mol} \mathrm{g}^{-1}$; Table 3). Noticeably, the K concentration increased about $65 \mu \mathrm{mol} \mathrm{g}{ }^{-1}$ compared to 542 unreacted column concentrations. In the high carbonate BPW columns, U concentration

543 decreased markedly to $3.8 \mu \mathrm{mol} \mathrm{g}^{-1}$, whileK decreased to a comparable concentration to quartz

544 control columns and Na was below detection (Table 3). For both minerals and column mixtures,

545 the concentrations of $\mathrm{Mg}$ and Ca were below detection, with the exception of Na-compreignacite

546 columns reacted with low carbonate BPW, which showed a measurable increase in $\mathrm{Mg}$ and Ca

547 compared to unreacted columns (Table 3).

\subsubsection{Structural changes after reaction from EXAFS spectroscopy}

549 Uranium-L $\mathrm{L}_{\text {III }}$ EXAFS spectra of K-compreignacite columns reacted with low and high 550 carbonate BPW (Table 5) were best fit by a linear combination (LC) of spectra of unreacted K551 compreignacite (78-88\%) and sorbed U(VI) on quartz (20-14\%).For Na-compreignacite reacted

552 with the low carbonate BPW, the spectrum was fit with a combination of unreacted K-

553 compreignacite (58\%), rather than unreacted Na-compreignacite, and a significant contribution

554 from the sorbed U(VI) on quartz spectrum (33\%), although the fit had a higher R-factorthan the 555 K-compreignacite LC fit (0.18 vs. 0.07). The spectrum of Na-compreignacite reacted with high 556 carbonate BPW was not fit well by LC of any reference spectra, and a single component fit with 557 K-compreignacite was a poor match $(\mathrm{R}$-factor $=0.25)$.

558 Shell-by-shell fits of K-compreignacite reacted with low and high carbonate BPWwere 559 initially based on the EXAFS fit of the unreacted K-compreignacite spectrum (Table 4). For both 560 spectra, the best fits showed no changes in $\mathrm{U}_{-} \mathrm{O}_{\mathrm{ax}}$ interatomic distances for the SS and MS paths 561 compared to unreacted K-compreignacite, but $\sigma^{2}$ decreased for the MS path (Table 5; Fig. 6 562 shows total fit results; deconvolutions of all backscattering paths are shown in Fig. S3 and S4 in 563 SI). The fits improved significantly when another $\mathrm{U}-\mathrm{O}_{\text {eq }}$ shell was included at a longer distance, 564 i.e., 2.81 and $2.88 \AA$ for high and low carbonate BPW samples, respectively. This shell 565 contributes to the FT peak between 2 and $2.8 \AA$ (Fig. 6). The additional U-O $\mathrm{O}_{\text {eq }}$ shell increased the 566 total equatorial oxygens from fitting to $\mathrm{N}=6.1-6.9$ ( $\sigma^{2}$ fixed). Backscattering amplitude from U567 U shells was greatly reduced compared with the unreacted spectrum, with U-U at 3.91-3.92 $\AA$ 568 the only detectable shell at distances beyond the equatorial oxygen atoms (Table 5). 
For reacted Na-compreignacite spectra, shell-by-shell fits were based on unreacted K- and Na-compreignacite models (Fig. 6, Table 5). As observed in the reacted K-compreignacite spectra, the fit of the low carbonate BPW Na-compreignacite spectrum was improved

572 significantly when a longer distance at $2.85 \AA$ was added for the $\mathrm{U}-\mathrm{O}_{\mathrm{eq}}$ shells. In high carbonate 573 BPW experiments, fits to the spectrum showed changes in the $\mathrm{U}-\mathrm{O}_{\mathrm{ax}}$ shell compared with unreacted compreignacite, with distance increasing to $1.84 \AA$. To obtain a better fit, the average $\sigma^{2}$ values of $U-\mathrm{O}_{\text {eq }}$ shells in the sorbed U(VI) model fit were used. However, the high carbonate BPW spectrum model included only three $\mathrm{U}_{-} \mathrm{O}_{\text {eq }}$ shells, with two predominant shorter distances at 2.22 and $2.39 \AA$, plus a longer distance shell at $2.90 \AA$ (Table 5). This distribution is similar to the unreacted Na-compreignacite fit model, although the longest $\mathrm{U}-\mathrm{O}_{\text {eq }}$ distance is longer than obtained in the spectrum fit of unreacted Na-compreignacite (Table 4). Backscattering from U-U shells was greatly reduced and only one $\mathrm{U}-\mathrm{U}$ shell was significant in the fit $(\mathrm{N}=1.0-2.4$ at 3.88$3.89 \AA$ ) of reacted compared to unreacted Na-compreignacite.

\subsection{Reactive transport simulation of dissolution}

The simulation of mineral dissolution using CrunchFlow under low carbonate BPW conditions considering only thermodynamicequilibrium (achieved by using high rate constants) resulted in $\mathrm{U}$ effluent concentrations reaching a steady-state withinthe first $10 \mathrm{PV}(5 \mathrm{~h})$ of the experiment thatwere about one order-of-magnitude higher than experimental observations. Concentrations of $\mathrm{U}$ set by equilibrium solubility of oxyhydroxide minerals schoepite and becquerelite were tested in the model with low carbonate BPW,and also resulted in onetotwo orders-of-magnitude higher dissolved U concentrations than observed (data not shown; solubility constants given in Table S3 in SI).In thehigh carbonate BPW systems, simulated dissolution under equilibrium conditions was rapid and mass decreased such that all U-mineral was dissolved bythe end of the experiment, instead of the observed gradual dissolution over time.

593 These initial tests verified that kinetically-controlled dissolution was a valid assumption for the 594 simulations and the RT-TST rate lawwas included in the model(Fig. 7 and Fig. S7 in SI).

For low carbonate BPW systems, effluent U concentrations were simulated well with the 596 kinetic RT-TST approach once apparent steady-state was reached (750-890 PV; 80-100 h in Fig. 5977 A1-B1). Based on the simulations, uranyl sorption on quartz(Fig. S6 in SI)was important for 598 retaining $U$ in the column only during initial reaction (80-100 h).Model simulations of effluent 
$\mathrm{pH}$ and TCwere constant from the first PVs and matched experimental concentrations at steady-

600 state, with the exception of TC concentrations in Na-compreignacite columns, which were

601 slightly overestimated by the model (Fig. 7 A2-B2 and A3-B3).Cation and anion concentrations

602 were simulated well, excluding the initial release of $\mathrm{K}$ and Na from K- and Na-compreignacite

603 columns and the K uptake from input solution by both minerals (Fig.S7 in SI).Optimized

604 dissolution rates $\left(\mathrm{R}_{\mathrm{s}}\right.$ and $\left.\mathrm{R}_{\mathrm{n}}\right)$ at apparent steady-state using the three calculation methods (SSD,

605 RT-TST and RT-TST-VF) are compared in Table 6.The SSD calculations producedfaster

606 dissolution rates than RT-TST optimized values, particularly for K-compreignacite $(\Delta \operatorname{logR}=0.84$

607 higher, or almost 7 times faster). Simultaneous optimization of mineral volume fraction $\left(\phi_{\mathrm{m}}\right)$ and

608 dissolution rate constant(RT-TST-VF method) resulted in no significant changes for either $\mathrm{R}_{\mathrm{s}}$ or

$609 \phi_{\mathrm{m}}$ in the low carbonate experiments (Table 6).

610 In the high carbonate BPW systems, the RT-TST modelwithout $\phi_{\mathrm{m}}$ optimization captured 611 the high initial U release followed by a slow decrease over time, but overestimated the U

612 concentrations after the first $200 \mathrm{PV}$ (25 h) (results not shown).However, effluent U, pH, and TC

613 were well matched for most of the experiment when the RT-TST-VF optimization model was

614 applied (Fig. 7). Although effluent $\mathrm{pH}$ was underestimated in the first part of the experiment,

615 thesimulations exhibited an increase over time that satisfactorily matched the $\mathrm{pH}$ evolution in

616 both mineral systems (Fig. 7 A2-B2). The TC simulated curves closely matched experimental

617 data for K-compreignacite after initial flush out (20 h), but simulationsslightly

618 underestimateddata for Na-compreignacite systems (Fig. 7 A3-B3). Effluent cation and anion

619 concentrations were also simulated well by the models, including decreasing $\mathrm{K}$ and Na effluent

620 in K- and Na-compreignacite systems, respectively (Fig.S7 in SI).The decrease in $\phi_{\mathrm{m}}$ for K- and

621 Na-compreignacite determined in the RT-TST-VF optimization (Table 6) compares well with the

$622 \mathrm{U}$ mass column loss calculated from total integrated U effluent (Table 2). For K-compreignacite,

623 average $\phi_{\mathrm{m}}$ decreased from $0.99 \%$ to $0.58 \%$ of total volume, and average U mass lost from the

624 column was $\sim 60 \%$ of the initial mass. For Na-compreignacite, $\phi_{\mathrm{m}}$ decreased from $0.51 \%$ to

$625 \quad 0.46 \%$ (mass loss of $87 \%$ ) forreplicate C, and from $0.50 \%$ to $0.31 \%$ (mass loss of $58 \%$ ) for

626 replicate $\mathrm{D}$ (Table 2$)$.

627 The three calculation methods showed that the difference between K- and Na-

628 compreignacite dissolution rates were within an order-of-magnitude in either low or high 
629 carbonate solutions. However, dissolution rates in the high carbonate BPW systems were higher 630 than in low carbonate systems by 2 to 3 orders-of-magnitude for both minerals, regardless of 631 thecalculation method.

\section{DISCUSSION}

\subsection{Dissolution rates}

For both minerals and both BPW systems, the dissolution of the uranyl oxyhydroxide minerals was kinetically controlled. Comparison of RT-TST optimized rates shows that

636 dissolution was 2.9-3.6 times faster for Na-compreignacite than for K-compreignacite in either BPW solution (Table 6, Fig.S8 in SI). Although mineral mass and surface area were higher in Kcompreignacite experiments compared to Na-compreignacite (Tables 2 and 3), normalization of the overall dissolution rate to the specific surface area and massamong all experiments showed this consistent result. A thermodynamic solubility study showed that substituting $\mathrm{Na}$ for $\mathrm{K}$ in the compreignacite structure increased the mineral solubility by approximately 3.5 orders-of-

642 magnitude (Gorman-Lewis et al., 2008b). In the dissolution experiments of this study, solutions 643 were at least 3 to 4 orders-of-magnitude undersaturated with respect to K- and Na-

644 compreignacite over the course of the experiment, and thus the contribution of the affinity term 645 in the TST rate law was negligible (Eq. 1).Therefore, the dissolution mechanism must have a key role in the rate difference between the two compreignacite compositions.

In the low carbonate BPW systems, SSD rates of both minerals were higher but within an order-of-magnitude of RT optimized values (Table 6). This is expectedas the optimization in the RT models was applied to effluent concentrations after initial high U flush-out, presumably of 650 mineral particles < $200 \mathrm{~nm}$ in size (Fig. 4 D1-D2), and apparent steady-state was reached. Under 651 these conditions, there was relatively little change in U mass in the column, and thus porosity,

652 because of the overall slow dissolutionrate. This interpretation is supported by the lack of 653 improvement of the fit to effluent data with $\phi_{m}$ optimization (RT-TST-VF). In the high carbonate 654 BPW systems, a clear steady-state was not reachedover the course of the experiment. Thus, the 655 SSD method was only applied to effluent data during the final 60-80 h when the dissolved U 656 concentrations were low. This resulted in lower dissolution rates than calculated by the RT-TST 657 optimization (Table 6), whichconsidered data from ca. 4-5 h.A flush-out in the first few pore 
658 volumes of smaller mineral particles (Fig.4 D1-D2) and possible colloidal U(VI) through the 0.2 $659 \mu \mathrm{m}$ filter could have reduced the total mineral mass available for dissolution. An over-estimation 660 of mass would cause the SSD rate (Eq.7) to be higher than that determined in the RT-TST 661 models, where $\phi_{\mathrm{m}}$, porosity, and chemical composition are updated at each time step.The 662 simultaneous optimization of $\mathrm{k}_{\mathrm{m}}$ and $\phi_{\mathrm{m}}$ using the RT-TST-VF approachconfirmed that the 663 amount of the dissolving mineral (and consequently the particle size and reactive surface 664 area)wassignificantly reduced over the course of the experiment in the high carbonate systems 665 and must be considered in the derivation of an overall dissolution rate.

666 Comparison of dissolution rates between low and high carbonate BPW solutions shows that 667 a10-fold increase of dissolved total carbonate concentration and corresponding increase in $\mathrm{pH}$ 668 (from 6.65 to 8.4 ) resulted in about 2.5-3 orders-of-magnitude fasterrate(Table 6, Fig.S8 in 669 SI).This increase agrees with previous observations for the dissolution of other silicate and 670 phosphate uranyl minerals. The dissolution rateof uranophane $\left(\mathrm{Ca}\left(\mathrm{H}_{3} \mathrm{O}\right)_{2}\left(\mathrm{UO}_{2}\right)_{2}\left(\mathrm{SiO}_{4}\right)_{2} \cdot 3 \mathrm{H}_{2} \mathrm{O}\right)$ in 671 flow experiments increased from $2.98 \cdot 10^{-11}$ to $5.89 \cdot 10^{-11} \mathrm{~mol} \mathrm{~m}^{-2} \mathrm{~s}^{-1}$ from $\mathrm{pH} 8$ to 9 and one 672 order-of-magnitude higher dissolved bicarbonate concentration(Pérez et al., 2000). For soddyite $673\left(\left(\mathrm{UO}_{2}\right)_{2} \mathrm{SiO}_{4} \cdot 2 \mathrm{H}_{2} \mathrm{O}\right)$, a uranyl silicate without interlayer cations, rates were on the order of $10^{-14}$ $674 \mathrm{~mol} \mathrm{~m}^{-2} \mathrm{~s}^{-1}$ with a very slight increase in the dissolution rate even with 10 times higher carbonate 675 concentration (Pérez et al., 1996). In a study of Ca-autunite $\left(\mathrm{Ca}\left(\mathrm{UO}_{2}\right)_{2}\left(\mathrm{PO}_{4}\right)_{2} \cdot 3 \mathrm{H}_{2} \mathrm{O}\right)$ dissolution 676 in batch flow-through experiments, overall uranium dissolution rates on the order of $10^{-11} \mathrm{~mol} \mathrm{~m}^{-}$ $677{ }^{2} \mathrm{~s}^{-1}$ at $\mathrm{pH}$ 7-8 were reported, and increased by 2 to 3orders-of-magnitude at $\mathrm{pH} 10-11$ and 6 fold 678 higher carbonate concentration (Gudavalli et al., 2013). The Na-endmember mineral $679\left(\mathrm{Na}\left(\mathrm{UO}_{2}\right)\left(\mathrm{PO}_{4}\right) \cdot 3 \mathrm{H}_{2} \mathrm{O}\right)$ was more stable than Ca-autunite (between 4 and 21 times lower 680 dissolution rate) and the rate increased by about one order-of-magnitude with higher $\mathrm{pH}$ and 681 carbonate. The overall dissolution rates calculated here for K- and Na-compreignacite in low 682 carbonate BPW solutions are lower by about 2 orders-of-magnitude than those reported by 683 Gudavalli et al (2013) for Ca-autunite at pH 7, but rates are similar or higher for K- and Na684 compreignacite in high carbonate BPW solution experiments at $\mathrm{pH}$ 8.4. Thesecontrasting rates 685 may be a consequence of intrinsic surface and structural differences between uranyl phosphate 686 and oxyhydroxide minerals, as well as differences between measurements in batch flow versus 687 porous media. 
Both K- and Na-compreignacite minerals incorporated $\mathrm{K}$ into the structure during dissolution experimentswith low carbonate BPW based on column effluent K concentration and bulk chemical analyses (control columns with quartz had no retardation of input solution species). Between 800-1400 PV (90-100 h) during steady-state U release in the Kcompreignacite column, effluent solution $\mathrm{K}$ decreased relative to influent concentration. By the end of the experiment, the total $\mathrm{K}$ concentration determined by acid digestion of the reacted column material had decreased relative to total $\mathrm{U}$, resulting in a ratio closer to the ideal 3:1 U:Kin stoichiometric compreignacite than in the unreacted mineral ( 2:1; Table 3). For Nacompreignacite, effluent $\mathrm{K}$ concentration was still significantly below input concentration by the end of the experiment and acid digestions of reacted column material showed a significant increase in $\mathrm{K}$, from below detection to almost four times the Na concentration, and a decrease in $\mathrm{Na}$ concentration. The U:cation ratio (considering $\mathrm{Na}$ and $\mathrm{K}$ content together)was 2.72, which is within error of the K-compreignacite reacted samples (Table 3). Uniquely among the reacted samples, analysis of Na-compreignacite showeda significant Ca concentration and a small amount of Mg after reaction, indicating that other exchangeable cations were alsoincorporated into the interlayer of the mineral structure for charge balance.Other studies have reported the formation of uranyl neoprecipitateson the mineral surface,as observed during the dissolution of becquerelite single crystals in batch, closed systems with ultrapure water $(\mathrm{pH} 7)$ for 24 h(Schindler et al., 2006; Schindler et al., 2011). In the flow-through porous media of our experiments, solutions were undersaturated with respect to uranyl phases, and thus cation exchange appears to be the mechanism of surface alteration of the original compreignacite minerals.

711 Uranyl oxyhydroxide minerals consistof U(VI)-OH polyhedral sheets thatincorporate a 712 variety of cations and water molecules into the interlayer and are held together by hydrogen 713 bonds(Burns, 1998; Burns and Hill, 2000) (Fig. 8).These low atomic number interlayer 714 speciesareweak photoelectron scatterers when present at distances $>\sim 3 \AA$, and thus do not 715 contribute detectable scattering amplitude to the EXAFS spectra.Nonetheless, changes in the 716 concentration, type, and charge of interlayer cations caninfluence interatomic distances between $717 \mathrm{U}(\mathrm{VI})$ and oxygen atoms in the polyhedral sheets, particularly for cations with a large ionic 
718 radius or higher charge (Allen et al., 1997; Kanematsu et al., 2014). Unreacted K-compreignacite 719 was stoichiometrically deficient in K compared to $\mathrm{U}$ (Table 3), which suggests that $\mathrm{H}^{+}\left(\mathrm{H}_{3} \mathrm{O}^{+}\right)$

720 accounts for charge balance. Analysis of EXAFS spectra by shell-by-shell fitting indicated more

721 disorder in U-U distances from adjacent uranyl polyhedral in unreacted K-compreignacite

722 compared with Na-compreignacite, which had an excess U:Nastoichiometric ratio (> 3),

723 although $\mathrm{U}-\mathrm{O}_{\mathrm{ax}}$ and $\mathrm{U}-\mathrm{O}_{\mathrm{eq}}$ shells and distances were similar in both compounds (Table 4). In

724 unreacted Na-compreignacite, U-U interatomic distances determined from EXAFS were more

725 similar to $\mathrm{U}$ shells in becquerelite $\left(\mathrm{Ca}\left(\mathrm{UO}_{2}\right)_{6} \mathrm{O}_{4}(\mathrm{OH})_{6} \cdot 8 \mathrm{H}_{2} \mathrm{O}\right)$ than in K-compreignacite (Table

726 4). After reaction for both compounds, $\mathrm{U}-\mathrm{O}_{\mathrm{eq}}$ bonding was more disordered (more oxygen shells

727 needed to fit the spectrum) and more distorted (greater range of bond distances), and long-range

728 order was diminished as shown by the lack of U-U scattering from adjacent polyhedra at long

729 distances (Table 5).Semi-quantitative spectral fitting by linear combinations of reference

730 compounds suggests that sorbed uranyl may contribute to the EXAFS after reaction ( 14-20\%

731 for K-compreignacite; 33\% but with poor fit results for Na-compreignacite), although the local

732 U-O bonding environment is similar for sorbed U(VI) and unreacted K- or Na-compreignacite

733 (Table 4) and thus difficult to distinguish. Although steady-state dissolution rates differed by 2-3

734 times between K- and Na-compreignacite (Table 6), the total fraction of U dissolved over the

735 course of all low BPW experiments was less than 1\%. The chemical and structural results show

736 that during flow-through reactive dissolution, $\mathrm{K}$ is preferentially taken up from solution in both

737 compounds, with $\mathrm{Na}$ exchanged from Na-compreignacite and $\mathrm{K}$ and minor divalent cations (Ca,

$738 \mathrm{Mg}$ ) incorporated into the Na-compreignacite interlayer.As such, both compounds resemble a

739 disordered K-compreignacite by the end of the experiment.

740 The overall reaction for stoichiometric dissolution of K- and Na-compreignacite mineralscan

741 be stated as:

$$
\mathrm{M}_{2}\left(\mathrm{UO}_{2}\right)_{6} \mathrm{O}_{4}(\mathrm{OH})_{6} \cdot 8 \mathrm{H}_{2} \mathrm{O}(\mathrm{s})+14 \mathrm{H}^{+} \leftrightarrow 6 \mathrm{UO}_{2}{ }^{2+}+2 \mathrm{M}^{+}+18 \mathrm{H}_{2} \mathrm{O}
$$

742 where $\mathrm{M}=\mathrm{K}$ or $\mathrm{Na}$. Optimization of $\mathrm{k}_{\mathrm{m}}$ using the TST rate law and parameter estimation in the 743 RT model (Eq. 6) included no dependence of the rate equation on the concentration of other 744 solution species and applied stoichiometric dissolution to Eq. 1. Interlayer cation exchange or 745 preferential leaching from the compreignacite structure was not included in the RT simulations. 746 The calculated overall dissolution rates using either the SSD ( $\left.\mathrm{R}_{\mathrm{n}}, \mathrm{Eq} .7\right)$ or RT-TST ( $\left.\mathrm{R}_{\mathrm{s}}, \mathrm{Eq.2}\right)$ 
747 methods were each normalized to the initial specific surfacearea $\left(A_{s}\right)$ of the mineral and were

748 dependent only on the total effluent $\mathrm{U}$ concentration. The difference between these two methods

749 for calculating R was, in the RT-TST optimization,the inclusion of sorption of aqueous uranyl on

750 quartz and flow through a porous medium. Based on the surface site concentration (Table S4 in

751 SI) and $U$ effluent concentrations, a maximum of 8-9\% and 18-19\% of the total $U$ dissolved from

752 K- and Na-compreignacite columns, respectively, could have sorbed on quartz (also suggested

753 by the EXAFS LC fits), and thus reduce the total U concentration measured in the effluent

754 solution. Inclusion of uranyl sorption in the RT-TST estimations should have resulted in an

755 optimized $R_{s}$ that was higher compared to the estimation of $R_{n}$ in SSD, for which all effluent $U$

756 was attributed to dissolution, since $U$ that is dissolved and then sorbed is retained in the

757 column.However, using the same range of experimental effluent data, calculated rates were

758 significantly lower for RT-TST optimization than using the SSD equation ( $\sim 7$ times lower forK-

759 compreignacite and $\sim 1.4$ times lower for Na-compreignacite columns), which indicates that

760 uranyl sorption does not account for the observed differences in calculated rates. The lack of

761 change in optimized $\mathrm{R}_{\mathrm{s}}$ between RT-TST and RT-TST-VF calculations is consistent with the

762 small fraction of mineral dissolved ( $<1 \%$ of total mass) and thus lack of change in porosity and

763 flow characteristics during dissolution.None of the rate calculations included interlayer cation

764 exchange and allassumed stoichiometric dissolution of compreignacite (Eq. 8). Slightly faster

765 dissolution rates calculated by all methods for Na-compreignacite compared with K-

766 compreignacite (Table 6) indicate that overall rates are relativelyinsensitiveto the exchange of

767 interlayer cations. These observations support the interpretation that the molecular-scale rate-

768 determining step is detachment of the uranyl group from the polyhedral layers of the mineral

769 structure (Fig. $8 \mathrm{~A}$ ), which occurs after $\mathrm{H}^{+}, \mathrm{OH}^{-}$or ionsin solution bond to surface O-atoms and

770 weaken the corresponding U-O-U bonds untilseparation(Schindler et al., 2004). The lower rates

771 calculated using the RT-TST governing equation to include flow through porous media

772 compared to the SSD method demonstrates the influence of pore-scale transport in reducing

773 apparent rates for a steady-state system in which net mineral dissolution is small and transport

774 properties are relatively constant. 


\subsection{Effect of dissolved carbonate on dissolution mechanism}

Increasing the concentration of dissolved carbonate in general accelerates the dissolution of uranyl minerals, particularly above pH 7(de Pablo et al., 1999; Gudavalli et al., 2013; Ilton et al., 2006; Pérez et al., 2000; Pérez et al., 1996; Sowder et al., 2001). In this study, an increase of one order-of-magnitude in the dissolved carbonate concentration resulted in fasterdissolution rates by 2-3 orders-of-magnitude (Table 6) and net removal of $U$ from the columns of $58-87 \%$ of the initial mass (Table 2). Electron microscopy of column material showed removal of fine particles and relatively clean quartz surfaces after reaction with high carbonate solutions (Fig. 5 B3-C3). Results from EXAFS analysis indicated a reduction in long-range atomic scattering from $U$ and changes in the distribution of $\mathrm{U}-\mathrm{O}_{\mathrm{eq}}$ bonding compared with compreignacite reacted in low carbonate BPW solutions. These results are consistent with a faster dissolution rate and congruent dissolution (i.e., no build-up of an extensive leached or altered surface layer) compared with low carbonate BPW experiments.

The effect of dissolved carbonate on enhancing dissolution has been reported for other uranyl minerals (e.g. Sowder et al. (2001)), yet the exact role of carbonate species on the dissolution mechanism is not always elucidated. For example in Ilton et al. (2006), the solubility of Na-boltwoodite was strongly enhanced by dissolved carbonate, but the relative importance or molecular details of the mechanism controlling the dissolution rate was not reported. Some studies inferred molecular mechanisms from aqueous speciation calculations.For example, Gudavalli et al. (2013)showed that during dissolution of Na- and Ca-autunite, buffered bicarbonate solutionswere undersaturated thermodynamically with respect to becquerelite, and uranylcarbonate andCa-uranyl carbonate complexes were the predominant aqueous species, which were postulated to control mineral dissolution.Uranylcarbonate and alkaline-earth uranyl carbonate complexes are highly soluble and stable species that dominate the uranyl aqueous speciation between pH 7 and 11(Bernhard et al., 1996; Bernhard et al., 2001; Kalmykov and Choppin, 2000) and also uranyladsorption onto sediment and soils (Stewart et al., 2010). Indeed, breakthrough of U(VI) was noticeably retarded by sorption to quartz in control columns with low carbonate BPW compared to high carbonate BPW systems(Control 2, Fig. 1 A1-B1, and Fig. S6 in SI).A recent review concluded thatreported differences in the inorganic speciation of $\mathrm{U}$ in natural waters were caused by whether or not the species $\mathrm{Ca}_{2} \mathrm{UO}_{2}\left(\mathrm{CO}_{3}\right)_{3}(\mathrm{aq})$, 
$805 \mathrm{CaUO}_{2}\left(\mathrm{CO}_{3}\right)_{3}{ }^{2-}$, and $\mathrm{MgUO}_{2}\left(\mathrm{CO}_{3}\right)_{3}{ }^{2-}$ were included in the thermodynamic database for the 806 equilibrium speciation calculations (Vercouter et al., 2015). Formation data for these ternary 807 species have been determined in the last decade (Dong and Brooks, 2006, 2008; Geipel et al., 808 2008; Lee and Yun, 2013), but few compiled thermodynamic databases have included them 809 (e.g.,they have been recently added to Thermochimie,www.thermochimie-tdb.com). In this 810 study, equilibrium speciation calculations of effluent column solutions, which included all 811 recently reported uranyl carbonate species (Table S3 in SI; Dong and Brooks (2006)), indicated 812 that the thermodynamically most stable aqueous uranyl species were $\mathrm{Ca}_{2} \mathrm{UO}_{2}\left(\mathrm{CO}_{3}\right)_{3}(\mathrm{aq})$, $813 \mathrm{CaUO}_{2}\left(\mathrm{CO}_{3}\right)_{3}{ }^{2-}$, and $\mathrm{MgUO}_{2}\left(\mathrm{CO}_{3}\right)_{3}{ }^{2-}$, comprising over $99 \%$ of dissolved uranyl in the high 814 carbonate BPW solutions (Fig. S9 in SI). Calculations also showed that K- and Na815 compreignacite and other common uranyl oxyhydroxide and carbonate phases were highly 816 undersaturated (by orders-of-magnitude) in these solutions.

817 In high carbonate BPW systems of $\mathrm{pH}>8$ and relatively high concentration of Ca (2.7 $\left.818 \mathrm{mmol} \mathrm{L}^{-1}\right)$ and $\mathrm{Mg}\left(0.83 \mathrm{mmol} \mathrm{L}^{-1}\right)$, we postulate that the dissolution of $\mathrm{K}$ - and Na819 compreignacite was driven by the formation of ternary Ca-uranyl carbonate complexes, and 820 possible Mg-uranyl carbonate complexes (Fig. 8 B).A proposed molecular mechanism can be 821 formulated from the process presented by Gudavalli et al. (2013) and de Pablo et al.(1999)for the 822 dissolution of Na- and Ca-autunite and $\mathrm{UO}_{2}$ minerals, respectively, in the presence of dissolved 823 carbonate. The two-step process consists ofsurface coordination of $\mathrm{Ca}^{2+}, \mathrm{CO}_{3}{ }^{2-}$ and $\mathrm{HCO}_{3}{ }^{-}$on the $824 \mathrm{U}(\mathrm{VI})$-oxygen polyhedral in the mineral layers, perhaps mostly on the edge sites, and then 825 detachment of the Ca-uranyl carbonate complexes from the surface into solution. Given the lack 826 of evidence for development of a surface leached or altered layer, it is likely that the overall 827 adsorption/desorption process is relatively fast, with the bond breaking of uranyl polyhedral as 828 the rate-determining step. The significant increase in dissolution rate between low and high 829 carbonate solutions suggests that the TST rate law (Eq. 1) used to describe overall mineral 830 dissolution should be modified to include a dependence on, for example, the concentration of 831 total carbonate or the concentrations of aqueous or adsorbed uranyl carbonate species $832\left(\mathrm{Ca}_{2} \mathrm{UO}_{2}\left(\mathrm{CO}_{3}\right)_{3}(\mathrm{aq}), \mathrm{CaUO}_{2}\left(\mathrm{CO}_{3}\right)_{3}{ }^{2-}, \mathrm{MgUO}_{2}\left(\mathrm{CO}_{3}\right)_{3}{ }^{2-}\right)$. Additional experimental data over a 833 range of dissolved carbonate concentrations are needed to adequately parameterize a rate law 834 that captures this mechanism in order to derive an intrinsic rate constant $\left(\mathrm{k}_{\mathrm{m}}\right)$ from fitting of the 835 overall rate $\left(\mathrm{R}_{\mathrm{m}}\right)$. 
836 Dissolution rates for both K- and Na-compreignacite calculated by the RT-TST model

$837\left(R_{S}\right)$ were faster than the rates calculated with the SSD equation $\left(R_{n}\right)$, but this difference is likely

838 due to the small data range used for the latter since constant release of $U$ was not achieved by the

839 end of the experiment. The RT-TST optimization failed to adequately capture U effluent

840 behavior over the entire experiment because the rapid rate of dissolution and uranyl transfer to

841 solution required correction for changing volume and reactive surface area of the mineral as

842 dissolution proceeded.The initial volume fraction of either K- or Na-compreignacite was $<1 \%$ of

843 the total column volume. As such, removal from columns of $>60 \%$ of initial $U$ would have little

844 effect on total porosity or bulk transport properties, which are controlled by the quartz matrix.

845 Transport properties calculated from $\mathrm{Br}$ tracer fits showed differences of $<5 \%$ between the

846 beginning and the end of the end of each experiment, and control and experimental columns had

847 a similar range of values for fluid velocity and dispersivity (Table 2,Fig. S1 in SI).Calculated

848 changes in total porosity by the end of the experiment due to mineral dissolution were $<0.6 \%$.

849 Although variation in mineral volume fraction $\left(\phi_{\mathrm{m}}\right)$ affects total porosity $(\phi)$ (Eq. 4), and thus

850 transport properties in the column (Eq. 6), variation in physical properties among different

851 column packing of quartz was greater on average than the change in porosity from uranyl

852 mineral dissolution alone. Therefore, optimization ofcompreignacite $\phi_{\mathrm{m}}$ in the RT-TST-VF

853 calculation was used to account primarily for the effect of changing particle mass, volume, and

854 surface area over the course of the experiment in the absence of a constant U effluent

855 concentration. Derivation of dissolution rates using a RT model while accounting for dynamic

856 changes in reactive surface area captures an average rate that does not require the system to

857 exhibit constant effluent concentrations (i.e., "steady-state”).

\section{CONCLUSIONS}

This study reports for the first time dissolution rates of two environmentally relevant uranyl oxyhydroxide minerals, K-compreignacite and Na-compreignacite. The overall dissolution rates

861 reported here were determined from packed-column experiments of the synthetic mineral

862 endmember mixed with quartz to simulate reaction dynamics in a porous medium. A reactive 863 transport model (CrunchFlow) was used to calculate overall dissolution rates normalized to 864 surface area $\left(R_{s}\right)$ while accounting for variation in reactive surface area and fluid transport over 865 the course of the dissolution experiment, rather than attempting to quantify a kinetic rate constant 
$866\left(k_{m}\right)$ that relates to elementary reaction steps (e.g., Lichtner (2016)). Characterization of column 867 material before and after reaction by a combination of bulk methods, microscale imaging, and 868 EXAFS spectroscopy provided insight into molecular-scale processes.

869 Findings of this study show that during flow-through reactive dissolution in low carbonate 870 solutions:

871 1. Interlayer cations were initially leachedout from the minerals. In Na-compreignacite, $\mathrm{K}$ and 872 minor divalent cations are exchanged for $\mathrm{Na}$ and incorporated into theinterlayer, destabilizing the mineral structure and slightly increasing thedissolution rate.

875 disordered K-compreignacite with altered surfaces.

2. The total fraction of $U$ dissolved over the course of the experiments was $<1 \%$ of initial mass, and thus mineral mass and transport properties did not change during the experiment. Dissolution rates calculated using a fully transient reactive transport model were slower than those calculated using a steady-state dissolution assumption, demonstrating the effect of including pore-scale transport on overall rates of mineral dissolution.

3. Calculated dissolution rates did not consider exchange of interlayer cations and assumed stoichiometric dissolution. If the molecular-scale rate-determining step is detachment of the uranyl group from the polyhedral layers of the mineral structure, this process is relatively insensitive to bonding with interlayer cations and results in similar overall dissolution rates.

4. A 10-fold increase in dissolved total carbonate concentration and corresponding increase in $\mathrm{pH}$ (from 6.65 to 8.4 ) resulted in about 2.5-3 orders-of-magnitude faster dissolution rate for K- and Na-compreignacite, net removal of 58-87\% of initial U mass from the columns, and lack of development of a surface leached or altered layer.

5. Faster dissolution and non-steady-state $U$ release required a model that accounted for decrease in U mass, volume, and reactive surface area over the course of the experiments. Optimization of both dissolution rate and mineral volume fraction in the reactive transport model resulted in faster ratescompared with a steady-state dissolution assumption, with Nacompreignacite dissolving slightly faster than K-compreignacite ( $\log R=-9.24$ vs. -9.81 mol 
$\left.\mathrm{m}^{2} \mathrm{~s}^{-1}\right)$. The small uranyl mineral mass and volume fraction $(<1 \%)$ compared to the quartz matrix in the columns did not affect column transport properties. Thus, calculated dissolution rates captured an average rate that accounted for significant change in particle volume and reactive surface area over the course of the experiment.

6. We postulate that faster dissolution of $\mathrm{K}$ - and Na-compreignacite was driven mostly by the formation of ternary Ca-uranyl carbonate complexes. These aqueous complexes dominate uranyl speciation in solution and increase in stability with increasing $\mathrm{pH}$. It is likely that adsorption of $\mathrm{Ca}^{2+}, \mathrm{CO}_{3}{ }^{2-}$ and $\mathrm{HCO}_{3}{ }^{-}$on $\mathrm{U}(\mathrm{VI})$-oxygen surface sites is a relatively fast process, whereas the detachment of Ca-uranyl carbonate complexes from mineral polyhedral layers was the rate-determiningstep.

Uranyl oxyhydroxide minerals such as compreignacite are formed easily from oxidation of reduced U minerals (compared to uranyl phosphates and silicates) and precipitate readily from saturated solutions (Hunter and Bertsch, 1998; Kanematsu et al., 2014; Morris et al., 1996). Their fast dissolution rates in natural waters, especially in the presence of high dissolved carbonate, compared with uranyl phosphate and silicate phases emphasizes the need for quantification of 910 coupled reaction and transport processes that control the concentration and fate of $U$ in surface 911 and subsurface environments.

\section{ACKNOWLEDGEMENTS}

913 This research was funded by the Subsurface Biogeochemical Research Program within the U.S.

914 Department of Energy, Office of Science, Office of Biological and Environmental Research, 915 under Grant No. SBR-DE-SC0006781. Portions of this research were carried out at the Stanford

916 Synchrotron Radiation Lightsource, a national user facility operated by Stanford University on 917 behalf of the U.S. Department of Energy, Office of Basic Energy Sciences. The authors would 918 like to thank the Environmental Analytical Laboratory and the Imaging and Microscopy Facility, 919 both atthe University of California Merced, for access to the analytical and imaging 920 instrumentation used in this research, and Dr. Bruce K. McNamara from PNNL for assisting with 921 TGA, FT-IR and Raman spectroscopy data collection. 
923 Allen, P.G., Shuh, D.K., Bucher, J.J., Edelstein, N.M., Palmer, C.E.A., Marquez, L.N., 1997. 924 EXAFS spectroscopic studies of uranium (VI) oxide precipitates. Mater. Res. Soc. Symp. Proc. 925 432, 139-143.

926 Batuk, D.N., Shiryaev, A.A., Kalmykov, S.N., Batuk, O.N., Romanchuk, A.Y., Shirshin, E.A., 927 Zubavichus, Y.V., 2011. Sorption and speciation of uranium on silica colloids, in: Kalmykov, 928 S.N., Denecke, M.A. (Eds.), Actinide Nanoparticle Research. Springer Berlin Heidelberg, pp. 929 315-332.

930 Bernhard, G., Geipel, G., Brendler, V., Nitsche, H., 1996. Speciation of uranium in seepage 931 waters of a mine tailing pile studied by time-resolved laser-induced fluorescence spectroscopy 932 (TRLFS). Radiochim. Acta 74, 87.

933 Bernhard, G., Geipel, G., Reich, T., Brendler, V., Amayri, S., Nitsche, H., 2001. Uranyl(VI) carbonate complex formation: Validation of the $\mathrm{Ca}_{2} \mathrm{UO}_{2}\left(\mathrm{CO}_{3}\right)_{3}$ (aq.) species. Radiochim. Acta 89, 511.

Burns, P.C., 1998. The structure of compreignacite, $\mathrm{K}_{2}\left[\left(\mathrm{UO}_{2}\right)_{3} \mathrm{O}_{2}(\mathrm{OH})_{3}\right]_{2}\left(\mathrm{H}_{2} \mathrm{O}\right)_{7}$. Can. Mineral. 36, 1061-1067.

Burns, P.C., Deely, K.M., Skanthakumar, S., 2004. Neptunium incorporation into uranyl compounds that form as alteration products of spent nuclear fuel: Implications for geologic repository performance. Radiochim. Acta 92, 151-159.

943 Burns, P.C., Li, Y., 2002. The structures of becquerelite and Sr-exchanged becquerelite. Am. 944 Mineral. 87, 550-557. oxidative dissolution mechanism of uranium dioxide. I. The effect of temperature in hydrogen carbonate medium. Geochim. Cosmochim. Acta 63, 3097-3103.

Doherty, J., 2015. Calibration and uncertainty analysis for complex environmental models. Watermark Numerical Computing, Brisbane, Australia.

Dong, W., Brooks, S.C., 2006. Determination of the formation constants of ternary complexes of uranyl and carbonate with alkaline earth metals $\left(\mathrm{Mg}^{2+}, \mathrm{Ca}^{2+}, \mathrm{Sr}^{2+}\right.$, and $\left.\mathrm{Ba}^{2+}\right)$ using anion exchange method. Environ. Sci. Technol. 40, 4689-4695.

953 Dong, W., Brooks, S.C., 2008. Formation of aqueous $\mathrm{MgUO}_{2}\left(\mathrm{CO}_{3}\right)_{3}{ }^{2-}$ complex and uranium 954 anion exchange mechanism onto an exchange resin. Environ. Sci. Technol. 42, 1979-1983.

955 Eagling, J., Worsfold, P.J., Blake, W.H., Keith-Roach, M.J., 2013. Influence of sediment redox 956 conditions on uranium mobilisation during saline intrusion. Chem. Geol. 357, 158-163. 
Finch, R.J., Buck, E.C., Finn, P.A., Bates, J.K., 1999. Oxidative corrosion of spent $\mathrm{UO}_{2}$ fuel in vapor and dripping groundwater at $90^{\circ} \mathrm{C}$. Mater. Res. Soc. Symp. Proc. 556.

Finch, R.J., Ewing, R.C., 1992. The corrosion of uraninite under oxidizing conditions. J. Nucl. Mater. 190, 133-156.

Finch, R.J., Murakami, T., 1999. Chapter 3. Systematics and paragenesis of uranium minerals, in: Burns, P.C., Finch, R. (Eds.), Reviews in Mineralogy, vol. 38: Uranium: mineralogy, geochemistry and the environment. Mineralogical Society of America, Washington DC, pp. 91180.

Geipel, G., Amayri, S., Bernhard, G., 2008. Mixed complexes of alkaline earth uranyl carbonates: A laser-induced time-resolved fluorescence spectroscopic study. Spectrochimica Acta Part A: Molecular and Biomolecular Spectroscopy 71, 53-58.

Giammar, D.E., Hering, J.G., 2004. Influence of dissolved sodium and cesium on uranyl oxide hydrate solubility. Environ. Sci. Technol. 38, 171-179.

Gorman-Lewis, D., Burns, P.C., Fein, J.B., 2008a. Review of uranyl mineral solubility measurements. J. Chem. Thermodyn. 40, 335-352.

Gorman-Lewis, D., Fein, J.B., Burns, P.C., Szymanowski, J.E.S., Converse, J., 2008b. Solubility measurements of the uranyl oxide hydrate phases metaschoepite, compreignacite, Nacompreignacite, becquerelite, and clarkeite. J. Chem. Thermodyn. 40, 980-990.

Grenthe, I., Fuger, J., Konings, R.J.M., Lemire, R.J., Muller, A.B., Nguyen-Trung, C., Wanner, H., 1992. Chemical thermodynamics of uranium. Elsevier, Paris, France.

Gudavalli, R.K.P., Katsenovich, Y.P., Wellman, D.M., Idarraga, M., Lagos, L.E., Tansel, B., 2013. Comparison of the kinetic rate law parameters for the dissolution of natural and synthetic autunite in the presence of aqueous bicarbonate ions. Chem. Geol. 351, 299-309.

Guillaumont, R., Fanghanel, T., Neck, V., Fuger, J., Palmer, D.A., Grenthe, I., Rand, M.H., 2003. Update on the chemical thermodynamics of uranium, neptunium, plutonium, americium and technetium. Elsevier, Paris.

Handley-Sidhu, S., Bryan, N.D., Worsfold, P.J., Vaughan, D.J., Livens, F.R., Keith-Roach, M.J., 2009. Corrosion and transport of depleted uranium in sand-rich environments. Chemosphere 77, 1434-1439.

Hazen, R.M., Ewing, R.C., Sverjensky, D.A., 2009. Evolution of uranium and thorium minerals. Am. Mineral. 94, 1293-1311.

Hunter, D.B., Bertsch, P.M., 1998. In situ examination of uranium contaminated soil particles by micro-X-ray absorption and micro-fluorescence spectroscopies. J. Radioanal. Nucl. Chem. 234, 237-242. 
ICDD, 1998. Powder Difraction Files. International Centre for Difraction Data, Newtown Square, PA.

993 Ilton, E.S., Liu, C.X., Yantasee, W., Wang, Z.M., Moore, D.A., Felmy, A.R., Zachara, J.M., 994 2006. The dissolution of synthetic Na-boltwoodite in sodium carbonate solutions. Geochim. 995 Cosmochim. Acta 70, 4836-4849.

996 Kalmykov, S.N., Choppin, G.R., 2000. Mixed $\mathrm{Ca}^{2+} / \mathrm{UO}_{2}{ }^{2+} / \mathrm{CO}_{3}{ }^{2-}$ complex formation at different ionic strengths. Radiochim. Acta 88, 603-606.

998 Kanematsu, M., Perdrial, N., Um, W., Chorover, J., O’Day, P.A., 2014. Influence of phosphate and silica on U(VI) precipitation from acidic and neutralized wastewaters. Environ. Sci. Technol. 48, 6097-6106.

Lee, J.-Y., Yun, J.-I., 2013. Formation of ternary $\mathrm{CaUO}_{2}\left(\mathrm{CO}_{3}\right)_{3}{ }^{2-}$ and $\mathrm{Ca}_{2} \mathrm{UO}_{2}\left(\mathrm{CO}_{3}\right)_{3}(\mathrm{aq})$

1002 complexes under neutral to weakly alkaline conditions. Dalton Trans. 42, 9862-9869.

1003 Lichtner, P.C., 1997. Chapter 1: Continuum formulation of multicomponent-multiphase reactive 1004 transport, in: Lichtner, P.C., Steefel, C.I., Oelkers, E.H. (Eds.), Reviews in Mineralogy, volume 1005 34: Reactive transport in porous media. Mineralogical Society of America, pp. 1 - 82.

1006

Lichtner, P.C., 2016. Kinetic rate laws invariant to scaling the mineral formula unit. Am. J. Sci. 316, 437-469.

1008 Liu, C., Zachara, J.M., Qafoku, N.P., Wang, Z., 2008. Scale-dependent desorption of uranium 1009 from contaminated subsurface sediments. Water Resour. Res. 44, W08413.

Malczewski, R.M., Inman Jr., W.D., 2007. Extraction strategies and silicone extractables, Technical Paper No. 52-1046-01. Dow Corning, p. 6. Morris, D.E., Allen, P.G., Berg, J.M., Chisholm-Brause, C.J., Conradson, S.D., Donohoe, R.J., 1014 Hess, N.J., Musgrave, J.A., Tait, C.D., 1996. Speciation of uranium in Fernald soils by molecular spectroscopic methods: characterization of untreated soils. Environ. Sci. Technol. 30, 2322-2331.

1023 Ravel, B., Newville, M., 2005. ATHENA, ARTEMIS, HEPHAESTUS: data analysis for X-ray 
1025

1026

1027

1028

1029

1030

1031

1032

1033

1034

1035

1036

1037

1038

1039

1040

1041

1042

1043

1044

1045

1046

1047

1048

1049

1050

1051

1052

1053

1054

1055

1056

1057

1058

Runkel, R.L., 1996. Solution of the advection-dispersion equation: Continuous load of finite duration. J. Environ. Eng. 122, 830-832.

Sandino, M.C.A., Grambow, B., 1994. Solubility equilibria in the U(VI)-Ca-K-Cl-H2O system: Transformation of schoepite into becquerelite and compreignacite. Radiochim. Acta 66/67, 3743.

Schindler, M., Hawthorne, F.C., Burns, P.C., Maurice, P.A., 2006. Dissolution of uranyl-oxidehydroxy-hydrate minerals. II. Becquerelite. Can. Mineral. 44, 1207-1225.

Schindler, M., Hawthorne, F.C., Mandaliev, P., Burns, P.C., Maurice, P.A., 2011. An integrated study of uranyl mineral dissolution processes: etch pit formation, effects of cations in solution, and secondary precipitation. Radiochim. Acta 99, 79-94.

Schindler, M., Mutter, A., Hawthorne, F.C., Putnis, A., 2004. Prediction of crystal morphology of complex uranyl-sheet minerals. I. Theory. Can. Mineral. 42, 1629-1649.

Sowder, A.G., Clark, S.B., Fjeld, R.A., 2001. The impact of mineralogy in the U(VI)-Ca-PO system on the environmental availability of uranium. J. Radioanal. Nucl. Chem. 248, 517-524.

Steefel, C.I., Appelo, C.A.J., Arora, B., Jacques, D., Kalbacher, T., Kolditz, O., Lagneau, V., Lichtner, P.C., Mayer, K.U., Meeussen, J.C.L., Molins, S., Moulton, D., Shao, H., Šimůnek, J., Spycher, N., Yabusaki, S.B., Yeh, G.T., 2015. Reactive transport codes for subsurface environmental simulation. Computat. Geosci. 19, 445-478.

Steefel, C.I., Maher, K., 2009. Fluid-rock interaction: A reactive transport approach. Rev. Mineral. Geochem. 70, 485-532.

Stewart, B.D., Mayes, M.A., Fendorf, S., 2010. Impact of uranyl-calcium-carbonato complexes on uranium(VI) adsorption to synthetic and natural sediments. Environ. Sci. Technol. 44, 928934.

Sylwester, E.R., Hudson, E.A., Allen, P.G., 2000. The structure of uranium (VI) sorption complexes on silica, alumina, and montmorillonite. Geochim. Cosmochim. Acta 64, 2431-2438.

Thompson, A., Steefel, C.I., Perdrial, N., Chorover, J., 2010. Contaminant desorption during long-term leaching of hydroxide-weathered Hanford sediments. Environ. Sci. Technol. 44, 19921997.

Ulrich, K.-U., Singh, A., Schofield, E.J., Bargar, J.R., Veeramani, H., Sharp, J.O., BernierLatmani, R., Giammar, D.E., 2008. Dissolution of biogenic and synthetic $\mathrm{UO}_{2}$ under varied reducing conditions. Environ. Sci. Technol. 42, 5600-5606.

Vercouter, T., Reiller, P.E., Ansoborlo, E., Février, L., Gilbin, R., Lomenech, C., Philippini, V., 2015. A modelling exercise on the importance of ternary alkaline earth carbonate species of uranium(VI) in the inorganic speciation of natural waters. Appl. Geochem. 55, 192-198. 
1059 Webb, S.M., 2005. SIXpack: a graphical user interface for XAS analysis using IFEFFIT. Phys. 1060 Scr. 2005, 1011.

1061 Wronkiewicz, D.J., Bates, J.K., Wolf, S.F., Buck, E.C., 1996. Ten-year results from unsaturated 1062 drip tests with UO2 at $90^{\circ} \mathrm{C}$ : implications for the corrosion of spent nuclear fuel. J. Nucl. Mater. 1063 238, 78-95.

1064 Zachara, J.M., Serne, J., Freshley, M., Mann, F., Anderson, F., Wood, M., Jones, T., Myers, D., 1065 2007. Geochemical processes controlling migration of tank wastes in Hanford's vadose zone.

1066 Vadose Zone J. 6, 985-1003.

1067 Zhu, C., 2009. Geochemical modeling of reaction paths and geochemical reaction networks. Rev. 1068 Mineral. Geochem. 70, 533-569.

1069

1070 


\section{Figures}

\section{Rates and mechanisms of uranyl oxyhydroxide mineral dissolution}

Estela REINOSO-MASET, Carl I. STEEFEL, Wooyong UM, Jon CHOROVER, Peggy A. O'DAY
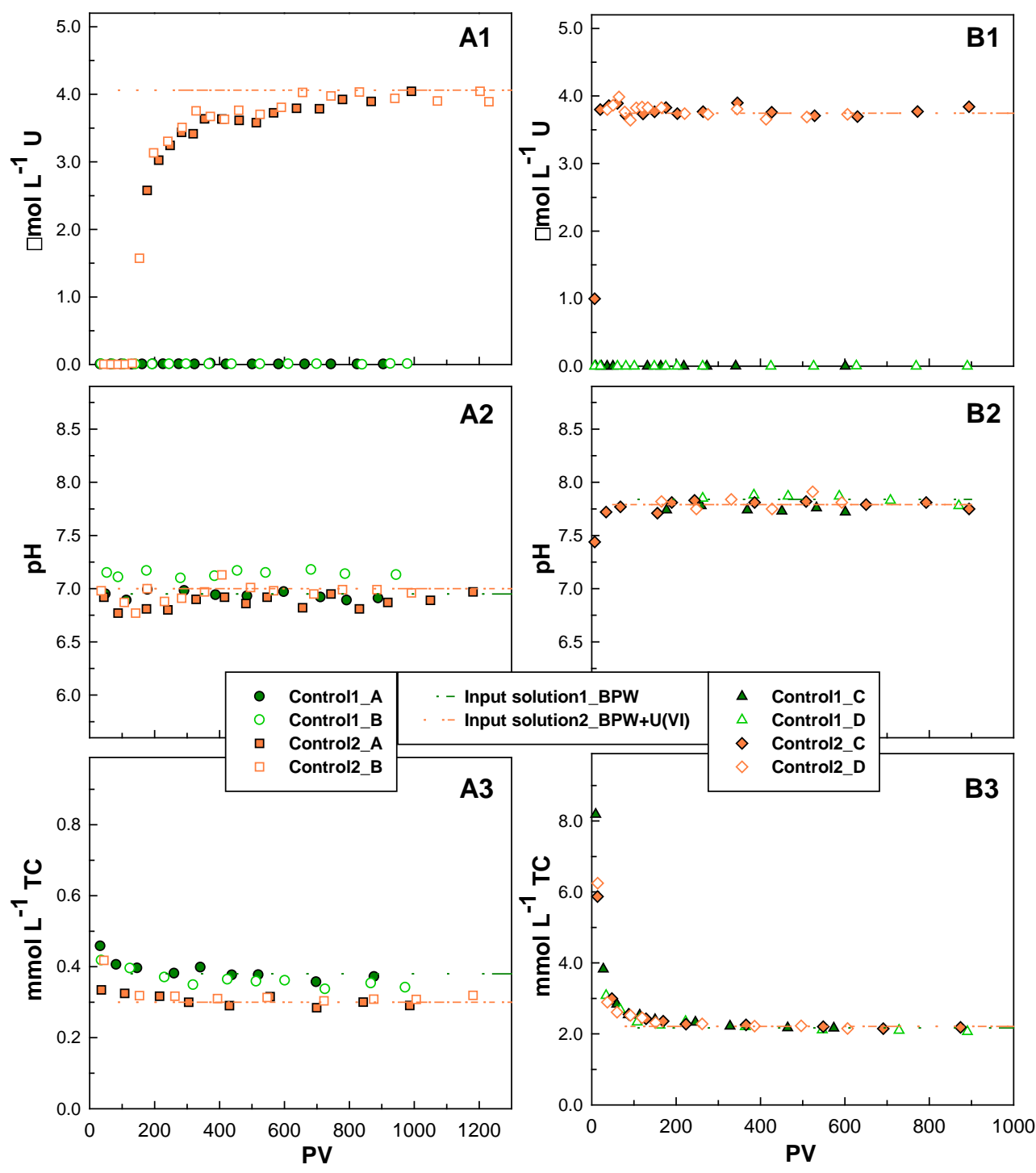

Figure 1.Duplicated control columns with quartz and no solid uranyl phases. Input solutions of background porewater (BPW) in Control 1 columns (green symbols) contain noU(VI); Control 2 columns (orange symbols) contain BPW with the addition of dissolved $\mathrm{U}(\mathrm{VI})\left(3.74-4.06 \mu \mathrm{mol} \mathrm{L}^{-1}\right)$. Dashed lines represent concentrations and $\mathrm{pH}$ of BPW input solutionswith (A) low $\left(0.30-0.38 \mathrm{mmol} \mathrm{L}^{-1}\right)$ and (B) high (2.17 - 2.21 $\mathrm{mmol} \mathrm{L}^{-1}$ ) total carbonate. A1, B1:dissolved U concentration (in $\left.\mu \mathrm{mol} \mathrm{L}^{-1}\right), \mathbf{A 2}, \mathbf{B 2}: \mathrm{pH}$, andA3, B3:dissolved total carbon ( $\mathrm{mmol} \mathrm{L}^{-1} \mathrm{TC}$ ) from effluent solutions as a function of time in pore volume(PV). 

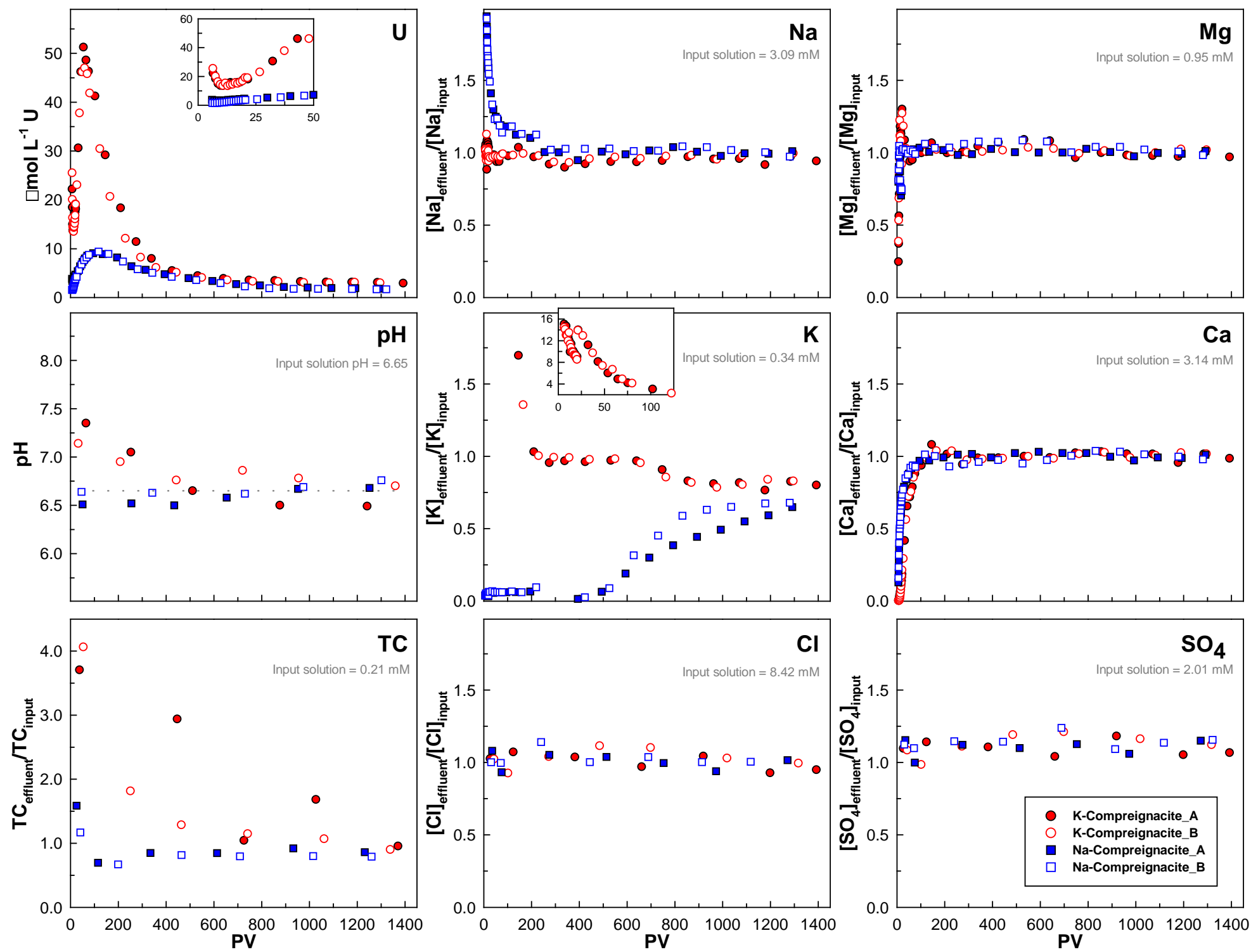

Figure 2.Concentration of released $\mathrm{U}$ (in $\mu \mathrm{mol} \mathrm{L}^{-1}$ ), effluent $\mathrm{pH}$, and total dissolved carbon (TC), $\mathrm{Na}, \mathrm{Mg}, \mathrm{K}, \mathrm{Ca}, \mathrm{Cl}_{\text {and }} \mathrm{SO}_{4}$ effluent concentrations respect to input solution measured over time (in pore volumes, PV) for duplicate K-compreignacite (red circles) and Nacompreignacite (blue squares) flow-through columns reacted with low carbonate BPW $\left(0.21 \mathrm{mmol} \mathrm{L}^{-1} \mathrm{TC}\right)$. The insets in U and K figuresshow data points for the first 50 and 125 PV respectively. 

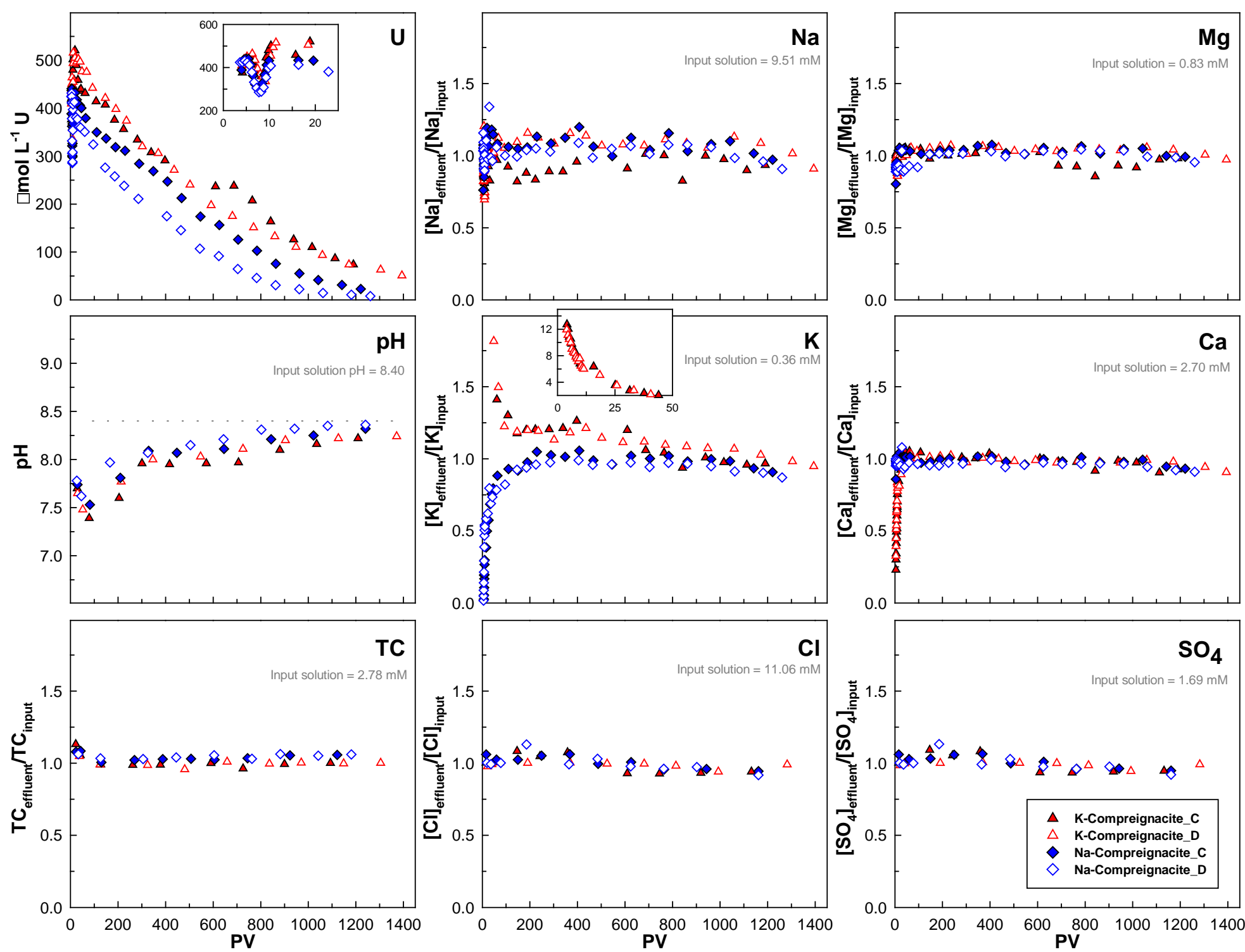

Figure 3. Concentration of released $\mathrm{U}$ (in $\mu \mathrm{mol} \mathrm{L}{ }^{-1}$ ), effluent $\mathrm{pH}$, and total dissolved carbon (TC), $\mathrm{Na}, \mathrm{Mg}, \mathrm{K}, \mathrm{Ca}, \mathrm{Cl}$ and $\mathrm{SO}_{4}$ effluent concentrations respect to input solution measured over time (in pore volumes, PV) for duplicate K-compreignacite (red triangles) and Nacompreignacite (blue diamonds) flow-through columns reacted with high carbonate BPW $\left(2.78 \mathrm{mmol} \mathrm{L}^{-1} \mathrm{TC}\right)$. The inset of $\mathrm{U}$ and $\mathrm{K}$ figureshow the data points for the first 25and 50 PV respectively. 

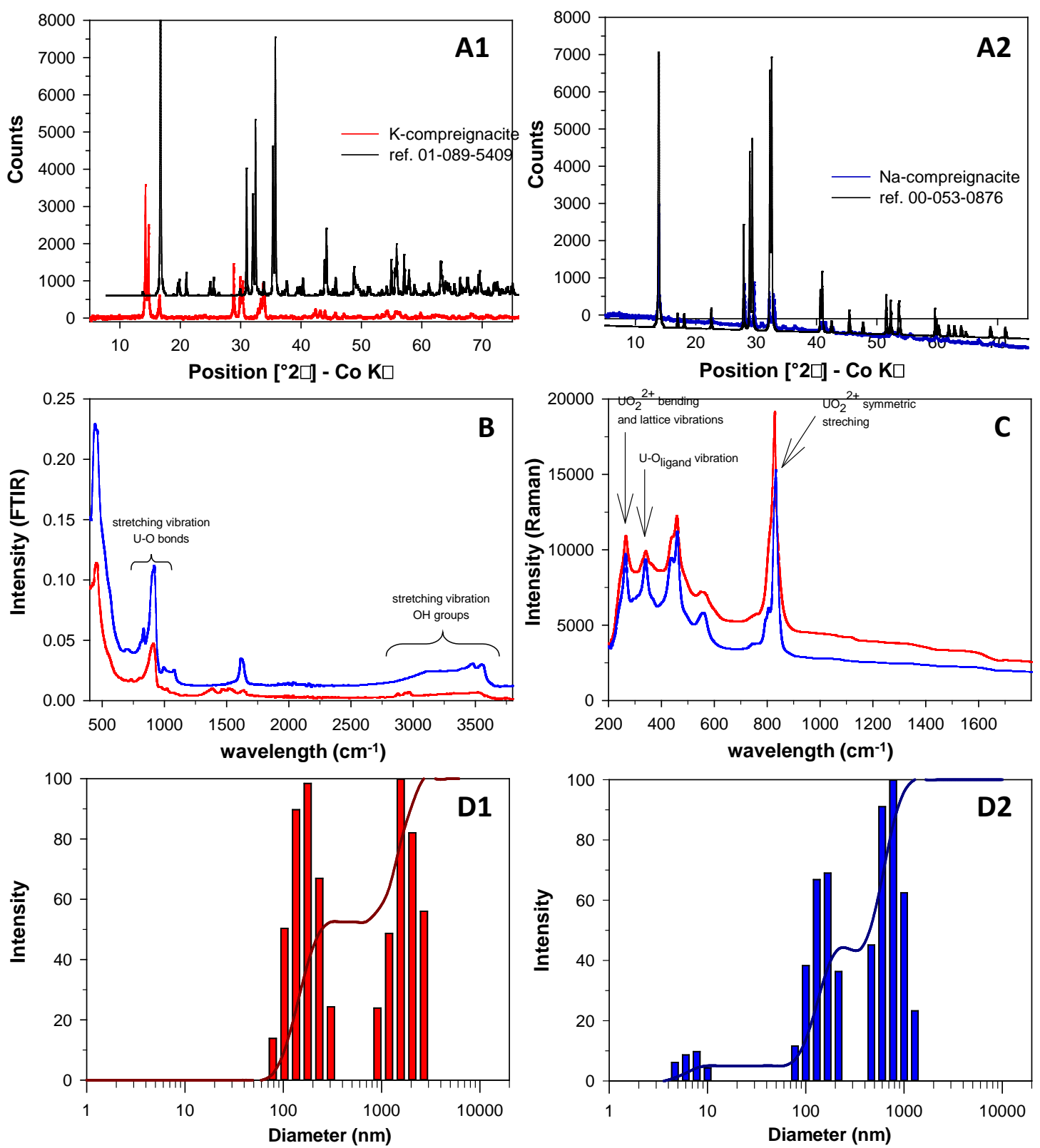

Figure 4. Characterization of unreacted solid phases: X-ray diffractograms for (A1) K-compreignacite and (A2) Na-compreignacite with their corresponding ICDD XRD reference patterns (black line spectra, ICDD card code number01-089-5409 for K-compreignacite and00-053-0876 for Na-compreignacite);FTIR (B) and Raman (C) spectra of K-compreignacite (red lines) and Na-compreignacite (blue lines); DSL particle size distribution for (D1) K-compreignacite and (D2) Na-compreignacite. 


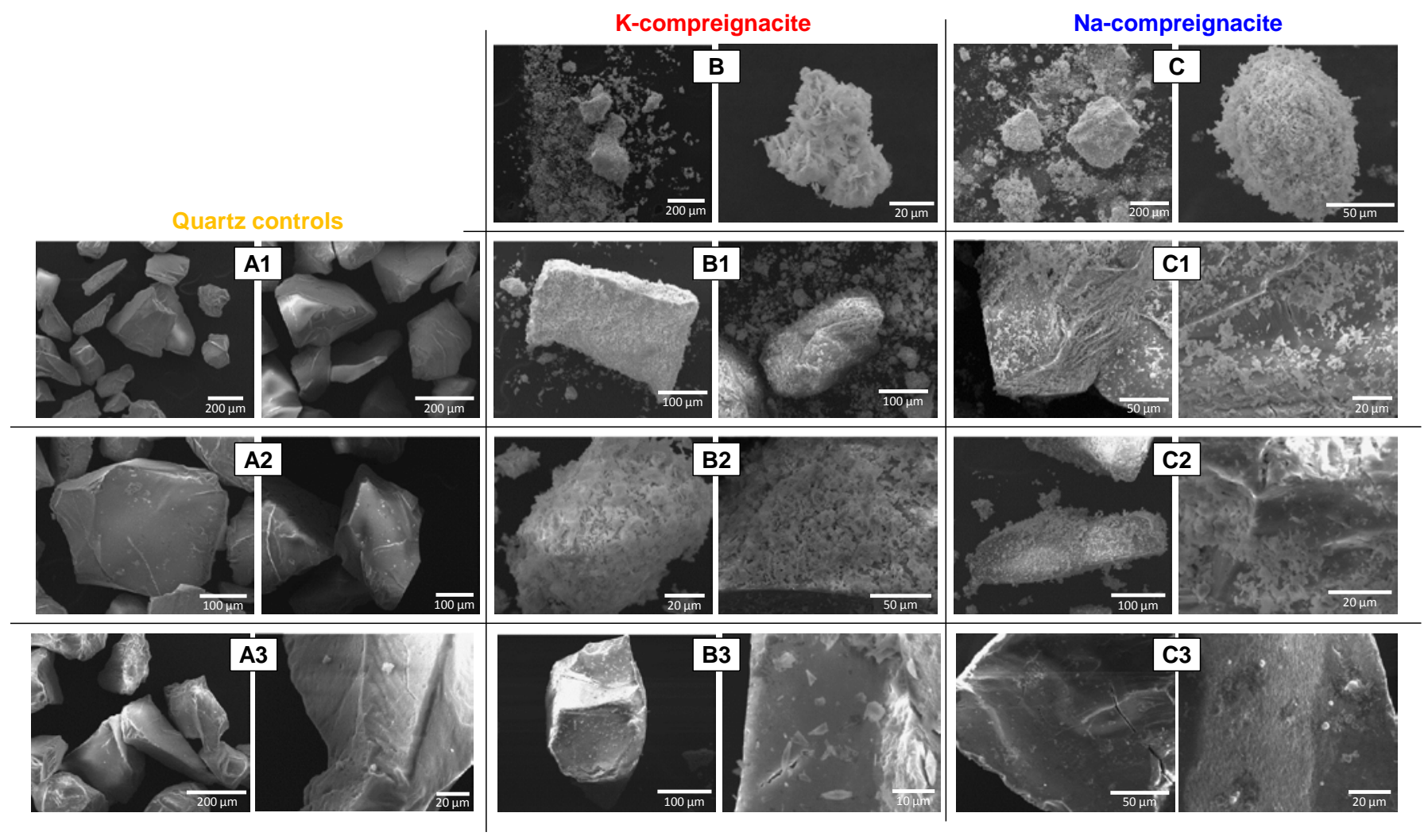

Figure5.Representative SEM images of control and uranyl oxyhydroxide mineral columns before and after reaction with low $\left(0.21 \mathrm{mmol} \mathrm{L}^{-1} \mathrm{TC}\right)$ and high $\left(2.78 \mathrm{mmol} \mathrm{L}^{-1} \mathrm{TC}\right)$ carbonate background porewater (BPW). Pure K-compreignacite and Na-compreignacite minerals are shown in $\mathbf{B}$ and Cimages respectively. Images of unreacted column mixtures (A1,B1, C1), column mixtures after reaction with low carbonate BPW (A2, B2, C2) and column mixtures after reaction with high carbonate BPW (A3, B3, C3) are shown for quartz only (A1-3), K-compreignacite with quartz (B1-3) and Na-compreignacite with quartz (C1-3). 


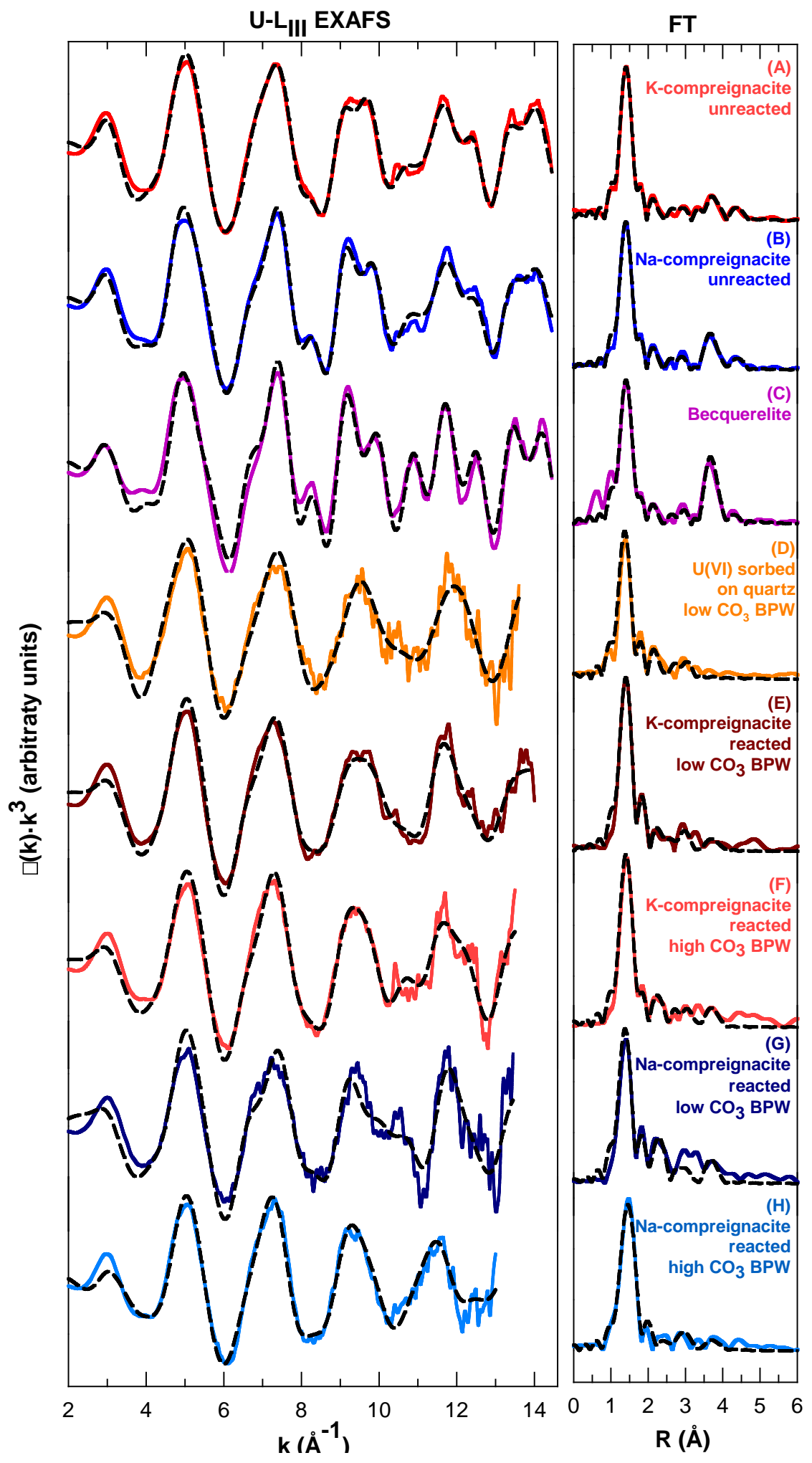

Figure 6. Uranium $\mathrm{L}_{\mathrm{III}}$-edge EXAFS spectra and Fourier Transforms (FT) ofunreacted K-compreignacite (A), Na-compreignacite (B) and becquerelite (C), U(VI) sorbed on quartz (D), reacted K-compreignacite with low (E) and high (F) carbonate BPW and reacted Na-compreignacite with low (G) and high (H) carbonate BPW. Total dissolved carbon for low and high carbonate BPW solutions was 0.21 and $2.78 \mathrm{mmol} \mathrm{L}^{-1} \mathrm{TC}$ respectively. Overlapping dashed black lines represent the non-linear least-squares fits (numerical fit results shown in Table 4 and 5) obtained by shell-by-shell fit.For detailed fit deconvolutions see Fig.S3 and S4in SI. 


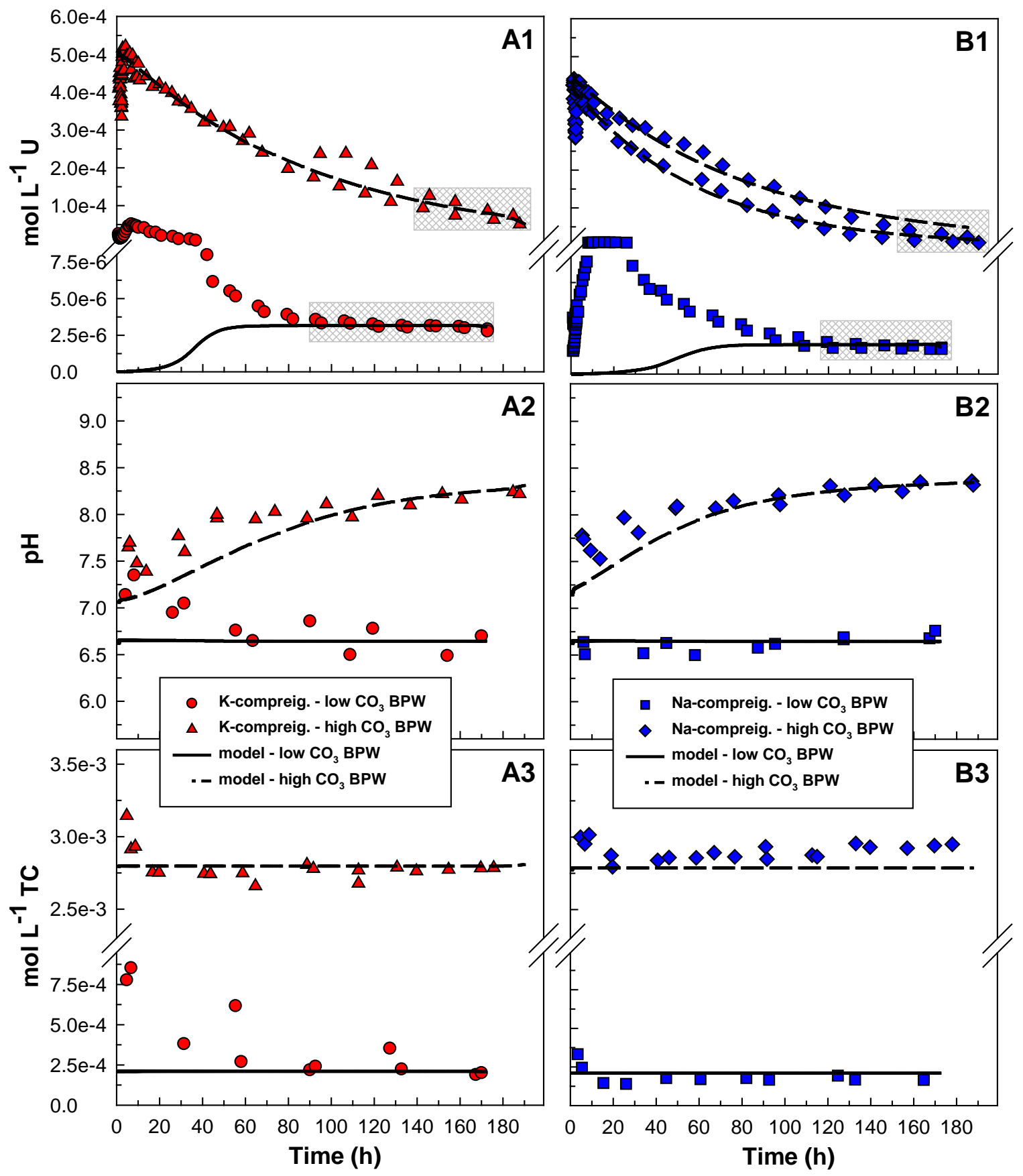

Figure 7.Reactive transport model simulations of effluent $U$ concentration (A1, B1), pH (A2, B2) and TC concentration (as $\mathrm{HCO}_{3}{ }^{-}$for the model) (A3, B3) for K-compreignacite (A1-3) and Na-compreignacite (B1-3) columns reacted with low and high carbonate background porewater (BPW). Symbols represent experimental data of duplicated columns. Note that y-axes for $\mathrm{U}$ and TC concentrations are broken for clarity.Solid and dashed lines represent averagedreactive transport model simulations(RT-TST-VF approach, Table 6) of duplicated columns for low and high carbonate BPW systems respectively, except for high carbonate BPW Na-compreignacite columns in B1, where individual simulations are plotted.Grey rectangle areas in A1 and B1indicate data points used for dissolution rate calculations using the SSD approach (Table 6). 


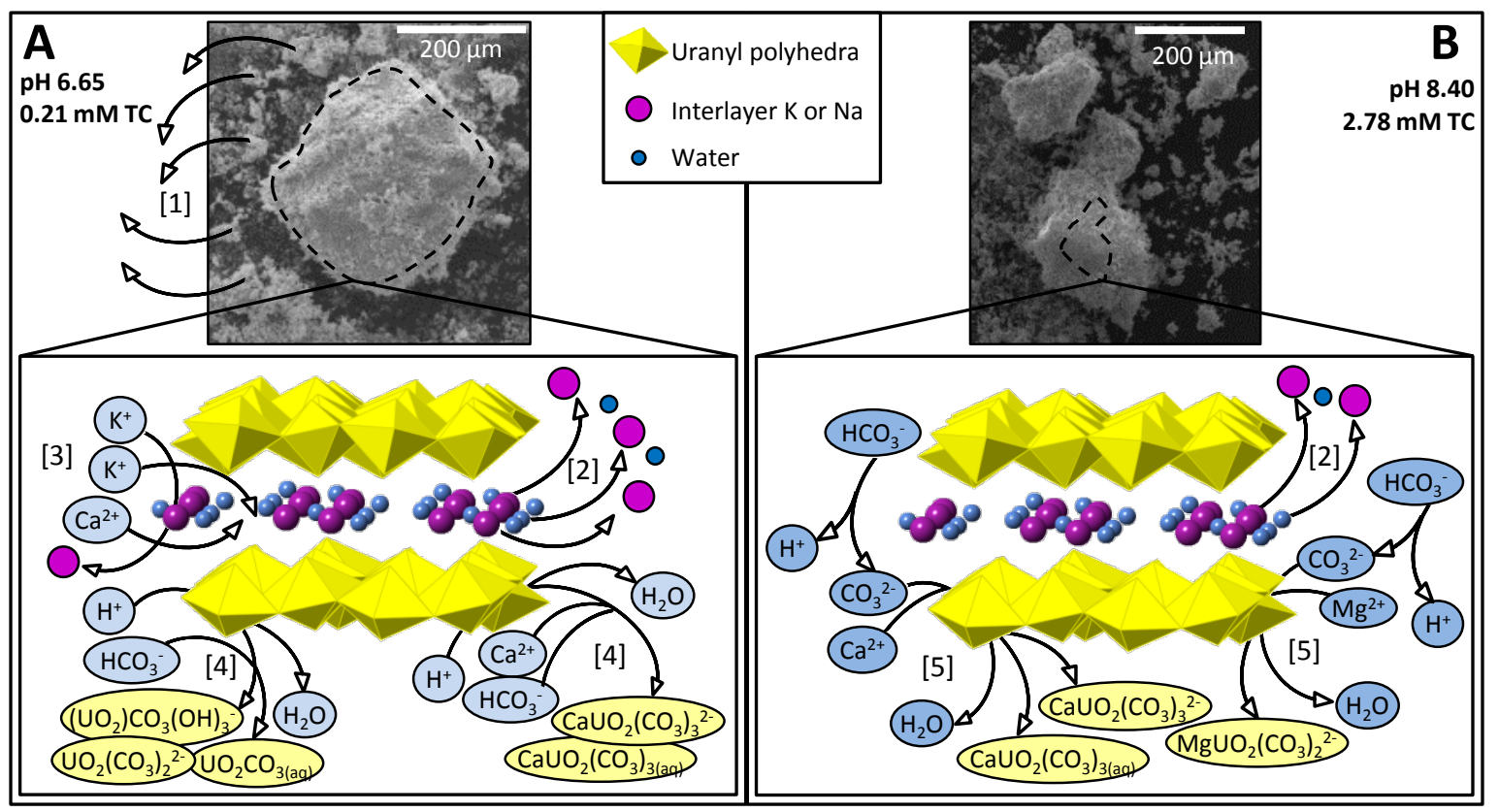

Figure 8.Schematic diagram showing the dissolution mechanisms for $\mathrm{K}$ - and Na-compreignacite mineral particles in low (A) and high (B) carbonate BPW flow-through column systems: [1] flush out of $<0.20$ $\mu \mathrm{m}$ mineral particles and [2] preferential leaching of interlayer cation in the first $200 \mathrm{PV}$;[3] cation exchange and/or incorporation into the mineral structure; [4] detachment of uranyl from mineral structure and formation of uranyl aqueous species (only the most abundant species are shown, Fig. S9 in SI); [5] formation and detachment of ternary $\mathrm{Ca}$ and $\mathrm{Mg}$ uranyl carbonate complexes. Dashed lines represent particle size by the end of the dissolution experiment (ca. $99 \%$ and $40 \%$ of original size in A and B, respectively). 


\section{Tables}

\section{Rates and mechanisms of uranyl oxyhydroxide mineral dissolution}

Estela REINOSO-MASET, CarII. STEEFEL, Wooyong UM, Jon CHOROVER,Peggy A. O'DAY

Table 1.Measured composition and $\mathrm{pH}$ of synthetic background porewater (BPW)used as input solutionsin control and uranyl minerals flow-through column experiments.

\begin{tabular}{|c|c|c|c|c|c|c|}
\hline \multirow[b]{3}{*}{ Column set } & \multicolumn{6}{|c|}{ Concentration $\left(\mathrm{mmol} \mathrm{L}^{-1}\right)^{a}$} \\
\hline & \multicolumn{3}{|c|}{ Low carbonate BPW } & \multicolumn{3}{|c|}{ High carbonate BPW } \\
\hline & Controls & Controls + U(VI) & U-minerals & Controls & Controls + U(VI) & U-minerals \\
\hline Column label & Ctl1_A/B & Ctl2_A/B & $\begin{array}{l}\text { K-Comp_A/B } \\
\text { Na-Comp_A/B }\end{array}$ & Ctl1_C/D & Ctl2_C/D & $\begin{array}{l}\text { K-Comp_C/D } \\
\text { Na-Comp_C/D }\end{array}$ \\
\hline $\mathrm{Na}$ & 3.05 & 2.92 & 3.09 & 3.56 & 3.61 & 9.51 \\
\hline Mg & 1.17 & 1.04 & 0.95 & 0.89 & 0.90 & 0.83 \\
\hline $\mathbf{K}$ & 0.43 & 0.37 & 0.34 & 0.32 & 0.33 & 0.36 \\
\hline $\mathrm{Ca}$ & 3.38 & 3.36 & 3.14 & 1.77 & 1.85 & 2.70 \\
\hline $\mathbf{C l}$ & 9.77 & 8.96 & 8.42 & 3.41 & 3.34 & 11.06 \\
\hline $\mathrm{SO}_{4}$ & 2.46 & 2.24 & 2.01 & 2.25 & 2.16 & 1.69 \\
\hline $\mathbf{T C}^{b}$ & 0.38 & 0.30 & 0.21 & 2.17 & 2.21 & 2.78 \\
\hline $\mathbf{U}^{c}$ & $\mathrm{n} / \mathrm{a}$ & $4.06 \cdot 10^{-3}$ & $\mathrm{n} / \mathrm{a}$ & $\mathrm{n} / \mathrm{a}$ & $3.74 \cdot 10^{-3}$ & $\mathrm{n} / \mathrm{a}$ \\
\hline$p H^{d}$ & 6.95 & 7.00 & 6.65 & 7.84 & 7.79 & 8.40 \\
\hline$I^{e}$ & 0.019 & 0.018 & 0.017 & 0.013 & 0.013 & 0.020 \\
\hline
\end{tabular}

\footnotetext{
${ }^{a}$ Errors associated with measurements were $\leq 2 \% \mathrm{RSD}$ for $\mathrm{Na}, \mathrm{Mg}, \mathrm{K}, \mathrm{Ca}$, and U concentrations, and $\leq 3 \% \mathrm{RSD}$ for $\mathrm{Cl}, \mathrm{SO}_{4}$, and TC concentrations.

${ }^{b}$ TC corresponds to dissolved total carbon.

${ }^{c}$ n/a: not applicable,input solutions containing no dissolved U(VI).

${ }^{d}$ Solution $\mathrm{pH}$ after transport through tubing.

${ }^{e}$ I corresponds to ionic strengthof the input solutions in $\mathrm{mol} \mathrm{L}^{-1}$.
} 
Table 2. Experimental conditions for control and K- and Na-compreignacite dissolution flow-through columns reactedwith low and high carbonate background porewater(BPW) as influent solutions.

\begin{tabular}{|c|c|c|c|c|c|c|c|c|c|c|c|c|c|c|c|c|c|c|}
\hline \multirow[t]{2}{*}{$\begin{array}{c}\text { Column } \\
\text { conditions }\end{array}$} & \multirow[t]{2}{*}{ Label } & \multicolumn{2}{|c|}{$\begin{array}{l}\text { Experiment } \\
\text { duration }\end{array}$} & \multicolumn{2}{|c|}{ Mass in column } & \multirow{2}{*}{$\begin{array}{c}\begin{array}{c}\text { Fluid } \\
\text { volume } \\
(\mathbf{V})^{a}\end{array} \\
(\mathrm{~mL})\end{array}$} & \multicolumn{2}{|c|}{$\begin{array}{l}\text { Volume fraction } \\
\qquad\left(\phi_{\mathrm{m}}\right)^{b}\end{array}$} & \multirow[t]{2}{*}{$\begin{array}{c}\text { Porosity } \\
(\phi)^{b}\end{array}$} & \multirow{2}{*}{$\begin{array}{c}\text { Volumetric } \\
\text { flow rate } \\
(\mathbf{Q})^{c} \\
(\leq 2 \% \mathrm{RSD}) \\
\left(\mathrm{mL} \mathrm{min}^{-1}\right)\end{array}$} & \multirow{2}{*}{$\begin{array}{c}\text { Linear fluid } \\
\text { velocity }(v)^{d} \\
( \pm 0.003) \\
\left.(\mathrm{cm} \mathrm{min})^{-1}\right)\end{array}$} & \multirow{2}{*}{ 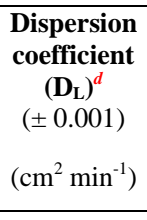 } & \multirow{2}{*}{$\begin{array}{c}\text { Dispersivity } \\
\left(\boldsymbol{\alpha}_{\mathrm{L}}\right)^{d} \\
( \pm 0.011) \\
\\
(\mathrm{cm}) \\
\end{array}$} & \multirow{2}{*}{$\begin{array}{c}\text { Peclet } \\
\text { number }^{d}\end{array}$} & \multirow{2}{*}{ 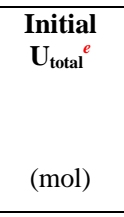 } & \multirow{2}{*}{$\begin{array}{c}\text { Dissolved } \\
\mathbf{U}_{\text {total }} \\
\\
(\mathrm{mol})\end{array}$} & \multicolumn{2}{|c|}{ Remaining $\mathbf{U}_{\text {total }}$} \\
\hline & & (h) & (PV) & $\begin{array}{c}\text { Mixture } \\
(\mathrm{g})\end{array}$ & $\begin{array}{c}\text { U-mineral } \\
(\mathrm{g})\end{array}$ & & Quartz & U-mineral & & & & & & & & & (mol) & $\begin{array}{l}\% \text { of } \\
\text { initial }\end{array}$ \\
\hline \multirow{2}{*}{$\begin{array}{l}\text { Quartz + low } \\
\mathrm{CO}_{3} \mathrm{BPW}\end{array}$} & Ctl1_A & 154 & 905 & 1.7495 & - & 0.3451 & 0.6567 & - & 0.3433 & 0.035 & 0.068 & 0.006 & 0.083 & 24 & - & - & - & - \\
\hline & Ctl1_B & 154 & 979 & 1.8421 & - & 0.3102 & 0.6915 & - & 0.3085 & 0.034 & 0.068 & 0.004 & 0.053 & 38 & - & - & - & - \\
\hline \multirow{2}{*}{$\begin{array}{l}\text { Quartz + low } \\
\mathrm{CO}_{3} \mathrm{BPW}+ \\
4 \mu \mathrm{M} \mathrm{U}(\mathrm{VI})\end{array}$} & Ctl2_A & 154 & 991 & 1.8181 & - & 0.3192 & 0.6825 & - & 0.3175 & 0.044 & 0.084 & 0.004 & 0.051 & 39 & - & - & - & - \\
\hline & Ctl2_B & 154 & 1225 & 1.8524 & - & 0.3063 & 0.6953 & - & 0.3047 & 0.034 & 0.068 & 0.003 & 0.043 & 47 & - & - & - & - \\
\hline \multirow{2}{*}{$\begin{array}{l}\text { Quartz + high } \\
\mathrm{CO}_{3} \mathrm{BPW}\end{array}$} & Ctl1_C & 112 & 601 & 1.8651 & - & 0.3015 & 0.7001 & - & 0.2999 & 0.027 & 0.050 & 0.002 & 0.041 & 50 & - & - & - & - \\
\hline & Ctl1_D & 112 & 890 & 1.8351 & - & 0.3128 & 0.6888 & - & 0.3112 & 0.042 & 0.090 & 0.004 & 0.043 & 47 & - & - & - & - \\
\hline \multirow{2}{*}{$\begin{array}{l}\text { Quartz + high } \\
\mathrm{CO}_{3} \mathrm{BPW}+ \\
4 \mu \mathrm{M} \mathrm{U}(\mathrm{VI})\end{array}$} & Ctl2_C & 112 & 894 & 1.8558 & - & 0.3050 & 0.6966 & - & 0.3034 & 0.041 & 0.089 & 0.006 & 0.065 & 31 & - & - & - & - \\
\hline & Ctl2_D & 112 & 607 & 1.8730 & - & 0.2985 & 0.7031 & - & 0.2969 & 0.027 & 0.051 & 0.002 & 0.048 & 42 & - & - & - & - \\
\hline \multirow{2}{*}{$\begin{array}{l}\text { K-comp. + } \\
\text { quartz + low } \\
\mathrm{CO}_{3} \mathrm{BPW}\end{array}$} & K-Comp_A & 173 & 1392 & 1.9433 & 0.2363 & 0.3163 & 0.6407 & 0.0446 & 0.3147 & 0.037 & 0.063 & 0.002 & 0.036 & 55 & $6.88 \cdot 10^{-4}$ & $3.36 \cdot 10^{-6}$ & $6.84 \cdot 10^{-4}$ & 99.5 \\
\hline & K-Comp_B & 173 & 1381 & 1.9332 & 0.2351 & 0.3199 & 0.6374 & 0.0444 & 0.3182 & 0.037 & 0.060 & 0.002 & 0.039 & 52 & $6.84 \cdot 10^{-4}$ & $3.06 \cdot 10^{-6}$ & $6.81 \cdot 10^{-4}$ & 99.6 \\
\hline \multirow{2}{*}{$\begin{array}{l}\text { Na-comp. }+ \\
\text { quartz + low } \\
\mathrm{CO}_{3} \mathrm{BPW}\end{array}$} & Na-Comp_A & 173 & 1291 & 1.8735 & 0.1463 & 0.3253 & 0.6483 & 0.0281 & 0.3236 & 0.037 & 0.062 & 0.003 & 0.054 & 37 & $4.33 \cdot 10^{-4}$ & $1.53 \cdot 10^{-6}$ & $4.31 \cdot 10^{-4}$ & 99.6 \\
\hline & Na-Comp_B & 173 & 1321 & 1.8806 & 0.1469 & 0.3228 & 0.6508 & 0.0282 & 0.3211 & 0.038 & 0.067 & 0.003 & 0.049 & 45 & $4.34 \cdot 10^{-4}$ & $1.44 \cdot 10^{-6}$ & $4.33 \cdot 10^{-4}$ & 99.7 \\
\hline \multirow{2}{*}{$\begin{array}{l}\text { K-comp.+ } \\
\text { quartz + high } \\
\mathrm{CO}_{3} \mathrm{BPW}\end{array}$} & K-Comp_C & 190 & 1208 & 1.8109 & 0.0510 & 0.3314 & 0.6606 & 0.0098 & 0.3296 & 0.035 & 0.059 & 0.002 & 0.030 & 59 & $1.49 \cdot 10^{-4}$ & $9.26 \cdot 10^{-5}$ & $5.59 \cdot 10^{-5}$ & 37.7 \\
\hline & K-Comp_D & 190 & 1389 & 1.8598 & 0.0524 & 0.3132 & 0.6784 & 0.0100 & 0.3115 & 0.037 & 0.067 & 0.002 & 0.037 & 67 & $1.53 \cdot 10^{-4}$ & $8.87 \cdot 10^{-5}$ & $6.38 \cdot 10^{-5}$ & 41.7 \\
\hline \multirow{2}{*}{$\begin{array}{l}\text { Na-comp. }+ \\
\text { quartz + high } \\
\mathrm{CO}_{3} \mathrm{BPW}\end{array}$} & Na-Comp_C & 190 & 1238 & 1.8153 & 0.0264 & 0.3252 & 0.6715 & 0.0051 & 0.3234 & 0.035 & 0.063 & 0.002 & 0.031 & 63 & $7.80 \cdot 10^{-5}$ & $6.79 \cdot 10^{-5}$ & $1.04 \cdot 10^{-5}$ & 12.9 \\
\hline & Na-Comp_D & 190 & 1249 & 1.8062 & 0.0263 & 0.3286 & 0.6681 & 0.0050 & 0.3268 & 0.035 & 0.064 & 0.002 & 0.030 & 64 & $7.76 \cdot 10^{-5}$ & $4.56 \cdot 10^{-5}$ & $3.20 \cdot 10^{-5}$ & 41.3 \\
\hline
\end{tabular}

${ }^{a}$ Fluid volume $(\mathrm{mL})$ or pore volume $\left(\mathrm{cm}^{3}\right)=$ total column volume - quartz volume $-U$-mineral volume; total column volume $=1.0053 \mathrm{~cm}^{3} ;$ quartz volume $=\mathrm{g}$ of quartz / quartz density; quartz density $=2.65 \mathrm{~g} / \mathrm{cm}^{3} ; U$-mineral volume $=(\mathrm{g}$ of U-mineral / molecular weight $) * U$-mineral molar volume; compreignacite molar volume $=391.3 \mathrm{~cm}^{3} / \mathrm{g}$ (from http://database.iem.ac.ru/mincryst/).

${ }^{b}$ Volume fraction = solid phase volume / total column volume; porosity = pore volume / total column volume.

${ }^{c}$ Determined by weight of effluent column samples.

${ }^{d}$ Determined from fits of Br tracer breakthrough curves (Fig. S1 in SI); dispersivity $\alpha_{L}=D_{L} / v$; peclet number $=\left(v^{*} L / D_{L}\right)$ with $L($ column length) $=2 \mathrm{~cm}$

${ }^{e}$ Calculated from U-mineral quartz mixture preparation.

${ }^{f}$ Calculated from the curve area integration of $U$ released during dissolution. 
Table 3.Solid phase characterization ofK- and Na-compreignacite synthetic minerals,uranyl mineral and quartz column mixtures, and quartz-only control columns,unreacted and reacted with low and highcarbonate background porewater (BPW).

\begin{tabular}{|c|c|c|c|c|c|c|c|c|}
\hline & & & & Eleme & I analysis ( & $\boldsymbol{o}\left(\boldsymbol{g}^{-1}\right)^{d}$ & & \\
\hline Sam & & $\begin{array}{c}N_{2}-B E T S S A^{c} \\
\left(m^{2} g^{-1}\right)\end{array}$ & {$[\mathrm{Na}]$} & {$[\mathrm{Mg}]$} & {$[\mathrm{K}]$} & {$[\mathrm{Ca}]$} & [U] & U:cation ratio ${ }^{e}$ \\
\hline Quartz & unreacted columns & $0.128 \pm 0.015$ & $6.1 \pm 0.7$ & $1.0 \pm 0.1$ & $1.2 \pm 0.4$ & $18.5 \pm 0.5$ & $<\mathrm{LOD}$ & $\mathrm{n} / \mathrm{a}$ \\
\hline & reacted low $\mathrm{CO}_{3} \mathrm{BPW}$ & $0.115 \pm 0.005$ & $1.1 \pm 0.4$ & $0.2 \pm 0.2$ & $0.6 \pm 0.2$ & $3.0 \pm 0.1$ & $1.3 \pm 0.4$ & $\mathrm{n} / \mathrm{a}$ \\
\hline & reacted high $\mathrm{CO}_{3} \mathrm{BPW}$ & $0.132 \pm 0.008$ & $1.3 \pm 0.9$ & $0.5 \pm 0.4$ & $0.7 \pm 0.4$ & $6.2 \pm 0.1$ & $0.1 \pm 0.1$ & $\mathrm{n} / \mathrm{a}$ \\
\hline $\begin{array}{l}\text { K-compreignacite } \\
\mathrm{K}_{2}\left(\mathrm{UO}_{2}\right)_{6} \mathrm{O}_{4}(\mathrm{OH})_{6} \cdot \mathrm{nH}_{2} \mathrm{O}\end{array}$ & pure compound & $9.645 \pm 0.520$ & $<\mathrm{LOD}$ & $<$ LOD & $1233 \pm 24$ & $<\mathrm{LOD}$ & $2621 \pm 52$ & $2.13 \pm 0.05$ \\
\hline $6.60 \%$ mass loss $(\mathrm{n}=8)^{a}$ & unreacted column & $0.196 \pm 0.039$ & $1.6 \pm 0.5$ & $<$ LOD & $125 \pm 16$ & $<\mathrm{LOD}$ & $252 \pm 5$ & $2.02 \pm 0.22$ \\
\hline $\mathrm{MW}^{b}=2008.25$ & reacted low $\mathrm{CO}_{3} \mathrm{BPW}$ & $0.351 \pm 0.024$ & $0.3 \pm 0.1$ & $<\mathrm{LOD}$ & $29.0 \pm 0.3$ & $<\mathrm{LOD}$ & $75.9 \pm 0.2$ & $2.59 \pm 0.02$ \\
\hline & reacted high $\mathrm{CO}_{3} \mathrm{BPW}$ & $0.122 \pm 0.004$ & $<\mathrm{LOD}$ & $<$ LOD & $6.6 \pm 2.5$ & $<\mathrm{LOD}$ & $16.2 \pm 1.7$ & $2.67 \pm 0.93$ \\
\hline $\begin{array}{l}\text { Na-compreignacite } \\
\mathrm{Na}_{2}\left(\mathrm{UO}_{2}\right)_{6} \mathrm{O}_{4}(\mathrm{OH})_{6} \cdot \mathrm{nH}_{2} \mathrm{O}\end{array}$ & pure compound & $3.534 \pm 1.798$ & $662 \pm 13$ & $<\mathrm{LOD}$ & $<$ LOD & $<\mathrm{LOD}$ & $2499 \pm 50$ & $3.78 \pm 0.05$ \\
\hline $7.29 \%$ mass loss $(\mathrm{n}=8)^{a}$ & unreacted column & $0.291 \pm 0.008$ & $51 \pm 25$ & $<\mathrm{LOD}$ & $<\mathrm{LOD}$ & $<$ LOD & $194 \pm 110$ & $3.70 \pm 0.29$ \\
\hline $\mathrm{MW}^{b}=1976.03$ & reacted low $\mathrm{CO}_{3} \mathrm{BPW}$ & $0.284 \pm 0.033$ & $18 \pm 2$ & $0.3 \pm 0.1$ & $67.5 \pm 1.5$ & $18.0 \pm 0.3$ & $225 \pm 5$ & $2.72 \pm 0.48$ \\
\hline & reacted high $\mathrm{CO}_{3} \mathrm{BPW}$ & $0.104 \pm 0.009$ & $<\mathrm{LOD}$ & $<$ LOD & $0.5 \pm 0.4$ & $<\mathrm{LOD}$ & $3.8 \pm 1.1$ & $\mathrm{n} / \mathrm{a}$ \\
\hline
\end{tabular}


Table 4. Uranium $\mathrm{L}_{\mathrm{III}}$-edge EXAFS shell-by-shell fit results for unreacted uranyl minerals and U(VI) sorbed on quartz compared with interatomic distances reported in prior studies.

\begin{tabular}{|c|c|c|c|c|c|c|}
\hline \multicolumn{3}{|l|}{ U-L $\mathrm{LIII}_{\text {EXAFS fits }}{ }^{a}$} & \multicolumn{4}{|c|}{$\mathbf{X R D}^{d}$} \\
\hline Sample & A-B & $\mathbf{N}^{b}$ & $R(\AA)$ & $\sigma^{2}$ & $\mathrm{~N}$ & $R(\AA)$ \\
\hline K-compreignacite & $\mathrm{U}-\mathrm{O}_{\mathrm{ax}}$ & 2.0 & 1.82 & 0.0028 & 2 & $1.79-1.81$ \\
\hline$\left(\mathrm{N}_{\text {Usite }}=2\right)$ & $\mathrm{MS}_{\text {Oax }}$ & 4.0 & $3.65^{c}$ & 0.0073 & 2 & $3.59-3.62$ \\
\hline$\Delta \mathrm{E}_{0}(\mathrm{eV})=0.30$ & $\mathrm{U}-\mathrm{O}_{\text {eq }}$ & 2.0 & 2.24 & 0.0047 & 2 & $2.20-2.27$ \\
\hline \multirow[t]{7}{*}{$\mathrm{R}$-factor $=0.004$} & $\mathrm{U}-\mathrm{O}_{\text {eq }}$ & 2.0 & 2.38 & 0.0076 & 2 & $2.40-2.46$ \\
\hline & $\mathrm{U}-\mathrm{O}_{\mathrm{eq}}$ & 1.0 & 2.50 & 0.0049 & 0.67 & 2.57 \\
\hline & & & & & 0.33 & 2.85 \\
\hline & U-U & 1.5 & 3.69 & 0.0078 & 1.33 & 3.82 \\
\hline & U-U & 2.5 & 3.89 & $0.0078^{c}$ & 1.33 & 3.88 \\
\hline & & & & & 1.33 & 3.94 \\
\hline & U-U & 2.0 & 4.62 & 0.0086 & 2 & $4.61-4.63$ \\
\hline Na-compreignacite & $\mathrm{U}-\mathrm{O}_{\mathrm{ax}}$ & 2.0 & 1.81 & 0.0031 & & \\
\hline$\left(\mathrm{N}_{\text {Usite }}=2\right)$ & $\mathrm{MS}_{\text {Oax }}$ & 4.0 & $3.64^{c}$ & 0.0059 & & \\
\hline$\Delta \mathrm{E}_{0}(\mathrm{eV})=0.20$ & $\mathrm{U}-\mathrm{O}_{\mathrm{eq}}$ & 2.0 & 2.24 & 0.0052 & & \\
\hline \multirow[t]{4}{*}{$\mathrm{R}$-factor $=0.004$} & $\mathrm{U}-\mathrm{O}_{\mathrm{eq}}$ & 2.0 & 2.37 & 00083 & & \\
\hline & $\mathrm{U}-\mathrm{O}_{\text {eq }}$ & 1.0 & 2.50 & 0.0045 & & \\
\hline & U-U & 4.0 & 3.89 & 0.0091 & & \\
\hline & U-U & 2.0 & 4.59 & 0.0087 & & \\
\hline Becquerelite $^{e}$ & $\mathrm{U}-\mathrm{O}_{\mathrm{ax}}$ & 2.0 & 1.82 & 0.0028 & 2 & $1.77-1.82$ \\
\hline$\left(\mathrm{N}_{\text {Usite }}=6\right)$ & $\mathrm{MS}_{\text {Oax }}$ & 2.0 & $3.64^{c}$ & 0.0031 & 2 & $3.49-3.66$ \\
\hline$\Delta \mathrm{E}_{0}(\mathrm{eV})=-0.94$ & $\mathrm{U}-\mathrm{O}_{\text {eq }}$ & 3.0 & 2.26 & 0.0072 & 3 & $2.22-2.39$ \\
\hline \multirow[t]{3}{*}{$\mathrm{R}$-factor $=0.010$} & $\mathrm{U}-\mathrm{O}_{\mathrm{eq}}$ & 2.0 & 2.47 & $0.0072^{c}$ & 2 & $2.39-2.80$ \\
\hline & U-U & 4.0 & 3.88 & 0.0061 & 4 & 3.79-3.92 \\
\hline & U-U & 1.5 & 4.64 & 0.0108 & 1.5 & $4.52-4.64$ \\
\hline$U(V I)$ sorbed on quartz $f$ & $\mathrm{U}-\mathrm{O}_{\mathrm{ax}}$ & 2.0 & 1.81 & 0.0029 & & $1.76-1.79$ \\
\hline$\Delta \mathrm{E}_{0}(\mathrm{eV})=-0.98$ & $\mathrm{MS}_{\text {Oax }}$ & 4.0 & $3.62^{c}$ & 0.0041 & & \\
\hline \multirow[t]{2}{*}{$\mathrm{R}$-factor $=0.036$} & $\mathrm{U}-\mathrm{O}_{\text {eq }}$ & 2.45 & 2.28 & 0.0053 & & $2.24-2.26$ \\
\hline & $\mathrm{U}-\mathrm{O}_{\mathrm{eq}}$ & 2.12 & 2.48 & $0.0053^{c}$ & & $2.48-2.50$ \\
\hline
\end{tabular}

${ }^{a} A-B$ is the absorber-backscatterer pair (MS = multiple scattering for 4 leg paths), $N$ is the coordination number, $R$ is the interatomic distance in $\AA, \sigma^{2}$ (Debye-Waller factor) is the absorber-backscatterer mean-square relative displacement, $\Delta E_{0}$ is the energy shift in $\mathrm{eV}$ from the least-squares fit, and R-factor is a goodness-of-fit parameter.

${ }^{b}$ Parameter fixed or constrained in least-squares fit.

${ }^{c}$ Parameter linked in the fit to the parameter directly above.

${ }^{d}$ Interatomic distances calculated from published crystal structure refinements from $X$-ray diffraction: i) $\mathrm{K}$ compreignacite from Burns (1998) and ii) becquerelite from Burns and Li (2002).

${ }^{e}$ Becquerelite spectrum obtained from Kanematsu et al. (2014); shell-by-shell parameters were re-fit for this work. ${ }^{f}$ Interatomic distances $(R)$ and $N$ for $U(V I)$ sorbed on quartz were based on EXAFS fit results reported in Sylwester et al. (2000)and Batuk et al. (2011)for sorbed aqueous uranyl on silicaand silica colloids in pH 6.46 and 6.5 experiments, respectively. 
Table 5.Linear combination and shell-by-shell fits of U $\mathrm{L}_{\mathrm{III}}$-edge EXAFS for K-compreignacite and Nacompreignacite reacted with low and highcarbonate background porewater (BPW).

\begin{tabular}{|c|c|c|c|c|c|c|c|c|c|}
\hline & Linear $\mathrm{C}$ & bination fits $^{a}$ & & & Shell-by-shell fit & & & & \\
\hline Sample & K-comp & Sorbed U(VI) & Sum & R-factor & & A-B & $\mathrm{N}$ & $R(\AA)$ & $\sigma^{2}$ \\
\hline \multirow{7}{*}{$\begin{array}{l}\text { Reacted } \\
\text { K-compreignacite } \\
\text { low } \mathrm{CO}_{3} \mathrm{BPW}\end{array}$} & \multirow[t]{7}{*}{0.788} & \multirow[t]{7}{*}{0.197} & \multirow[t]{7}{*}{0.985} & \multirow[t]{7}{*}{0.070} & $\Delta \mathrm{E}_{0}(\mathrm{eV})=0.44$ & $\mathrm{U}-\mathrm{O}_{\mathrm{ax}}$ & $2.0^{c}$ & 1.80 & 0.0028 \\
\hline & & & & & $\mathrm{R}$-factor $=0.011$ & $\mathrm{MS}_{\text {Oax }}$ & $4.0^{c}$ & $3.61^{d}$ & 0.0030 \\
\hline & & & & & & $\mathrm{U}-\mathrm{O}_{\mathrm{eq}}$ & 1.7 & 2.26 & $0.0057^{c}$ \\
\hline & & & & & & $\mathrm{U}-\mathrm{O}_{\mathrm{eq}}$ & 2.6 & 2.40 & $0.0057^{d}$ \\
\hline & & & & & & $\mathrm{U}-\mathrm{O}_{\mathrm{eq}}$ & 0.9 & 2.59 & $0.0057^{d}$ \\
\hline & & & & & & $\mathrm{U}-\mathrm{O}_{\mathrm{eq}}$ & 0.9 & 2.88 & $0.0057^{d}$ \\
\hline & & & & & & U-U & 1.6 & 3.91 & $0.0078^{c}$ \\
\hline \multirow{7}{*}{$\begin{array}{l}\text { Reacted } \\
\text { K-compreignacite } \\
\text { high } \mathrm{CO}_{3} \mathrm{BPW}\end{array}$} & \multirow[t]{7}{*}{0.884} & \multirow[t]{7}{*}{0.146} & \multirow[t]{7}{*}{1.030} & \multirow[t]{7}{*}{0.077} & $\Delta \mathrm{E}_{0}(\mathrm{eV})=0.75$ & $\mathrm{U}-\mathrm{O}_{\mathrm{ax}}$ & $2.0^{c}$ & 1.82 & 0.0026 \\
\hline & & & & & $\mathrm{R}$-factor $=0.017$ & $\mathrm{MS}_{\mathrm{Oax}}$ & $4.0^{c}$ & $3.65^{d}$ & $0.0026^{d}$ \\
\hline & & & & & & $\mathrm{U}-\mathrm{O}_{\text {eq }}$ & 2.5 & 2.26 & $0.0057^{c}$ \\
\hline & & & & & & $\mathrm{U}-\mathrm{O}_{\mathrm{eq}}$ & 1.3 & 2.37 & $0.0057^{d}$ \\
\hline & & & & & & $\mathrm{U}-\mathrm{O}_{\mathrm{eq}}$ & 1.9 & 2.52 & $0.0057^{d}$ \\
\hline & & & & & & $\mathrm{U}-\mathrm{O}_{\text {eq }}$ & 1.2 & 2.81 & $0.0057^{d}$ \\
\hline & & & & & & U-U & 1.5 & 3.92 & $0.0078^{c}$ \\
\hline \multirow{7}{*}{$\begin{array}{l}\text { Reacted } \\
\mathrm{Na} \text {-compreignacite } \\
\text { low } \mathrm{CO}_{3} \mathrm{BPW}\end{array}$} & \multirow[t]{7}{*}{0.583} & \multirow[t]{7}{*}{0.331} & \multirow[t]{7}{*}{0.914} & \multirow[t]{7}{*}{0.180} & $\Delta \mathrm{E}_{0}(\mathrm{eV})=0.86$ & $\mathrm{U}-\mathrm{O}_{\mathrm{ax}}$ & $2.0^{c}$ & 1.81 & 0.0035 \\
\hline & & & & & $\mathrm{R}$-factor $=0.061$ & $\mathrm{MS}_{\text {Oax }}$ & $4.0^{c}$ & $3.62^{d}$ & $0.0035^{d}$ \\
\hline & & & & & & $\mathrm{U}-\mathrm{O}_{\mathrm{eq}}$ & 2.6 & 2.30 & $0.0053^{c}$ \\
\hline & & & & & & $\mathrm{U}-\mathrm{O}_{\text {eq }}$ & 0.9 & 2.46 & $0.0053^{d}$ \\
\hline & & & & & & $\mathrm{U}-\mathrm{O}_{\text {eq }}$ & 1.6 & 2.57 & $0.0053^{d}$ \\
\hline & & & & & & $\mathrm{U}-\mathrm{O}_{\mathrm{eq}}$ & 2.0 & 2.85 & $0.0053^{d}$ \\
\hline & & & & & & U-U & 2.4 & 3.88 & $0.0091^{c}$ \\
\hline \multirow{6}{*}{$\begin{array}{l}\text { Reacted } \\
\mathrm{Na} \text {-compreignacite } \\
\text { high } \mathrm{CO}_{3} \mathrm{BPW}\end{array}$} & \multirow[t]{6}{*}{1.000} & & \multirow[t]{6}{*}{1.000} & \multirow[t]{6}{*}{0.250} & $\Delta \mathrm{E}_{0}(\mathrm{eV})=-0.30$ & $\mathrm{U}-\mathrm{O}_{\mathrm{ax}}$ & $2.0^{c}$ & 1.84 & 0.0034 \\
\hline & & & & & $\mathrm{R}$-factor $=0.011$ & $\mathrm{MS}_{\text {Oax }}$ & $4.0^{c}$ & $3.66^{d}$ & $0.0034^{d}$ \\
\hline & & & & & & $\mathrm{U}-\mathrm{O}_{\mathrm{eq}}$ & 2.7 & 2.22 & $0.0060^{c}$ \\
\hline & & & & & & $\mathrm{U}-\mathrm{O}_{\mathrm{eq}}$ & 2.2 & 2.39 & $0.0060^{d}$ \\
\hline & & & & & & $\mathrm{U}-\mathrm{O}_{\mathrm{eq}}$ & 0.5 & 2.90 & $0.0060^{d}$ \\
\hline & & & & & & U-U & 1.0 & 3.89 & $0.0078^{c}$ \\
\hline
\end{tabular}

${ }^{a}$ Linear combination fits were performed using K-compreignacite (K-comp), Na-compreignacite (Na-comp), becquerelite, schoepite, uranyl nitrate and U(VI) sorbed on quartz (sorbed U(VI)) reference spectra (from this work and Kanematsu et al. (2014)). Spectra contributing less than 10\% to the fit were discarded.

${ }^{b} A-B$ is the absorber-backscatterer pair (MS = multiple scattering for 4 leg paths), $N$ is the coordination number, $R$ is the interatomic distance in $\AA, \sigma^{2}$ (Debye-Waller factor) is the absorber-backscatterer mean-square relative displacement, $\Delta E_{0}$ is the energy shift in $\mathrm{eV}$ from the least-squares fit, and R-factor is a goodness-of-fit parameter. ${ }^{c}$ Parameter fixed or constrained in least-squares fits; $\sigma^{2}$ of U-Oeq shells were obtained from averaging $\sigma^{2}$ of reference spectra fits (Table 4).

${ }^{d}$ Parameter linked in the fit to the parameter directly above. 
Table 6.Dissolution rates normalized to mineral specific surface area (R,mol m$\left.{ }^{-2} \mathrm{~s}^{-1}\right)$ for $\mathrm{K}$ - and Nacompreignacite columns reacted with low and high carbonate background porewater (BPW) calculated from experimental U effluent concentrations using either a steady-state rate calculationor anoptimization with CrunchFlow/PEST to include reactive transport through porous media and changes in mineral volume fraction $\left(\phi_{\mathrm{m}}\right)$, porosity and chemical composition.

\begin{tabular}{|c|c|c|c|c|c|c|c|}
\hline & \multirow[b]{2}{*}{$\operatorname{method}^{a}$} & \multicolumn{3}{|c|}{ low $\mathrm{CO}_{3} \mathrm{BPW}$} & \multicolumn{3}{|c|}{ high $\mathrm{CO}_{3} \mathrm{BPW}$} \\
\hline & & $\phi_{\mathrm{m}}^{b}$ & 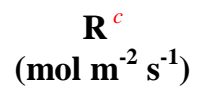 & $\log \mathbf{R}^{c}$ & $\phi_{\mathrm{m}}{ }^{b}$ & 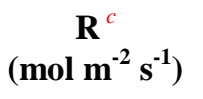 & $\log \mathbf{R}^{c}$ \\
\hline \multirow[t]{3}{*}{ K-compreignacite } & SSD & 0.0445 & $8.46 \cdot 10^{-13}$ & $-12.07 \pm 0.02$ & 0.0099 & $6.02 \cdot 10^{-11}$ & $-10.22 \pm 0.07$ \\
\hline & RT-TST & 0.0445 & $1.24 \cdot 10^{-13}$ & $-12.91 \pm 0.03$ & 0.0099 & $8.31 \cdot 10^{-11}$ & $-10.08 \pm 0.04$ \\
\hline & RT-TST-VF & 0.0430 & $1.28 \cdot 10^{-13}$ & $-12.89 \pm 0.01$ & 0.0058 & $1.57 \cdot 10^{-10}$ & $-9.81 \pm 0.07$ \\
\hline \multirow[t]{3}{*}{ Na-compreignacite } & SSD & 0.0282 & $5.01 \cdot 10^{-13}$ & $-12.30 \pm 0.04$ & 0.0051 & $8.11 \cdot 10^{-11}$ & $-10.09 \pm 0.32$ \\
\hline & RT-TST & 0.0282 & $3.63 \cdot 10^{-13}$ & $-12.44 \pm 0.03$ & 0.0051 & $4.06 \cdot 10^{-10}$ & $-9.39 \pm 0.03$ \\
\hline & RT-TST-VF & 0.0275 & $3.71 \cdot 10^{-13}$ & $-12.43 \pm 0.03$ & 0.0038 & $5.79 \cdot 10^{-10}$ & $-9.24 \pm 0.11$ \\
\hline
\end{tabular}

\footnotetext{
${ }^{a}$ SSD: steady-state dissolution (Eq. 7);RT-TST: reactive transport-transition state theory with optimization of rate constant $\left(k_{m}\right)$ (Eq.2 and 6); RT-TST-VF: reactive transport-transition state theory with simultaneous optimization of $k_{m}$ and $\phi_{m}(E q .2,3$ and 6).

${ }^{b}$ Volume fractioncalculated from initial mineral mass loaded in columns (average of duplicated columns); for RTTST-VF method, reported valuesare the $\phi_{m}$ after CrunchFlow/PEST optimization.

${ }^{c}$ Reported values are average of duplicate columns.
} 


\section{References}

Batuk, D.N., Shiryaev, A.A., Kalmykov, S.N., Batuk, O.N., Romanchuk, A.Y., Shirshin, E.A., Zubavichus, Y.V., 2011. Sorption and speciation of uranium on silica colloids, in: Kalmykov, S.N., Denecke, M.A. (Eds.), Actinide Nanoparticle Research. Springer Berlin Heidelberg, pp. 315-332.

Burns, P.C., 1998. The structure of compreignacite, $\mathrm{K}_{2}\left[\left(\mathrm{UO}_{2}\right)_{3} \mathrm{O}_{2}(\mathrm{OH})_{3}\right]_{2}\left(\mathrm{H}_{2} \mathrm{O}\right)_{7}$. Can. Mineral. 36, 1061-1067.

Burns, P.C., Li, Y., 2002. The structures of becquerelite and Sr-exchanged becquerelite. Am. Mineral. 87, 550-557.

Kanematsu, M., Perdrial, N., Um, W., Chorover, J., O’Day, P.A., 2014. Influence of phosphate and silica on U(VI) precipitation from acidic and neutralized wastewaters. Environ. Sci. Technol. 48, 6097-6106.

Sylwester, E.R., Hudson, E.A., Allen, P.G., 2000. The structure of uranium (VI) sorption complexes on silica, alumina, and montmorillonite. Geochim. Cosmochim. Acta 64, 2431-2438. 